\title{
User's Guide for PLTWIND Version 1.0: \\ PC-Based Software for Generating Plots of Monitored Wind Data and Gridded Wind Fields for Hanford Emergency Response Applications
}

C. S. Glantz

K. W. Burk

September 1995

Prepared for

the U.S. Department of Energy

under Contract DE-AC06-76RLO 1830

Pacific Northwest Laboratory

Richland, Wàshington 99352

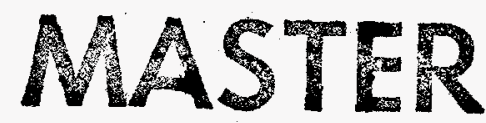




\section{DISCLAIMER}

Portions of this document may be illegible in electronic image products. Images are produced from the best available original document. 


\section{Summary}

This document is a user's guide for the PLoT Near-Surface WIND (PLTWIND) modeling system. PLTWIND is a personal-computer-based software product designed to produce graphical displays of Hanford wind observations and model-generated wind fields. The real-time wind data processed by PLTWIND are acquired from the mainframe computer system at the Hanford Meteorology Station and copied to PLTWIND systems by the Hanford Local Area Network (HLAN). PLTWIND is designed for operation on an IBM-compatible PC with a connection to the HLAN. An HP-compatible pen plotter or laser printer (with a minimum of 1.5 megabytes of memory and a Plotter-in-a-Cartridge hardware) is required to generate hardcopies of PLTWIND's graphical products.

PLTWIND's products are intended for use by emergency response personnel in evaluating atmospheric dispersion characteristics in the near-surface environment. Model products provide important atmospheric information to hazard evaluators; however, these products are only tools for assessing near-surface atmospheric transport and should not be interrupted as providing definitive representation of atmospheric conditions. 



\section{Acknowledgments}

The authors would like to thank Eric Skyllingstad for the development of some of the graphical algorithms that were incorporated in PLTWIND. The authors would like to thank J. Van Ramsdell and George Athey for their contributions to the development of the MESOI model, portions of which are used in PLTWIND to generated wind fields. Finally, the authors would like to thank Eric Stephan for his technical guidance and skilled testing of PLTWIND during code development, Regina Lundgren for her review of the document, Teresa Riley for document production, and Sharon Daly for communications support. 



\section{Contents}

Summary $\ldots \ldots \ldots \ldots \ldots \ldots \ldots \ldots \ldots \ldots \ldots \ldots \ldots \ldots \ldots \ldots$

Acknowledgments $\ldots \ldots \ldots \ldots \ldots \ldots \ldots \ldots \ldots \ldots \ldots \ldots \ldots \ldots$

1.0 Introduction $\ldots \ldots \ldots \ldots \ldots \ldots \ldots \ldots \ldots \ldots \ldots \ldots \ldots \ldots \ldots \ldots$

1.1 Hardware and Operating System Requirements for PLTWIND . . . . . . . . . 1.1

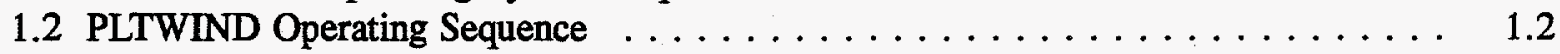

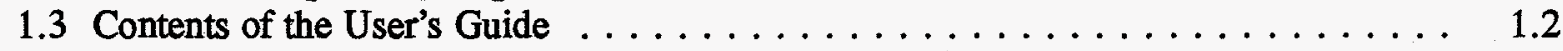

2.0 The Environmental Setting of the Hanford Site $\ldots \ldots \ldots \ldots \ldots \ldots \ldots$

3.0 Instructions on How to Use PLTWIND $\ldots \ldots \ldots \ldots \ldots \ldots \ldots \ldots \ldots \ldots$

3.1 Acquiring Meteorological Data File $\ldots \ldots \ldots \ldots \ldots \ldots \ldots \ldots \ldots \ldots \ldots$

3.2 Specifying the Desired Graphical Product $\ldots \ldots \ldots \ldots \ldots \ldots \ldots \ldots \ldots$

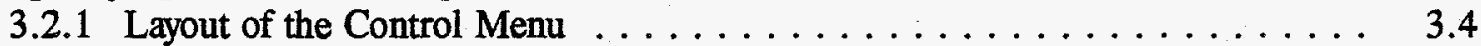

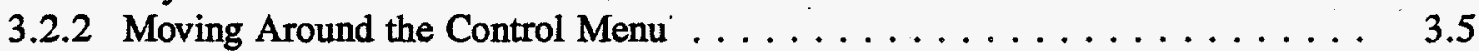

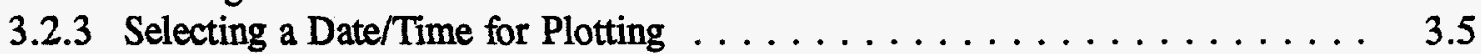

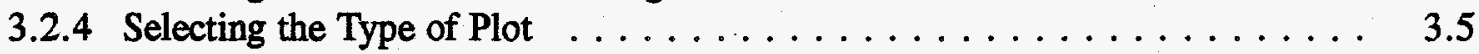

3.2 .5 Selecting Plot Options . . . . . . . . . . . . . . . . .

3.2.6 Executing Products, Accessing an Updated Meteorology File, and

Exiting the Model . . . . . . . . . . . . . . . . . 3.6

3.2.7 Error Detection During the Input of Parameters $\ldots \ldots \ldots \ldots \ldots \ldots . \ldots \ldots$

3.3 Generating a Graphical Product $\ldots \ldots \ldots \ldots \ldots \ldots \ldots \ldots \ldots \ldots \ldots \ldots \ldots$

3.4 Generating a Hardcopy of the Graphical Product $\ldots \ldots \ldots \ldots \ldots \ldots$

4.0 Summary of Key Instructions for PLTWIND $\ldots \ldots \ldots \ldots \ldots \ldots$

5.0 References $\ldots \ldots \ldots \ldots \ldots \ldots \ldots \ldots \ldots \ldots \ldots \ldots \ldots \ldots \ldots \ldots \ldots$

Appendix A - Climate and Behavior of Winds at the Hanford Site . . . . . . . . . A.1

Appendix B - PLTWIND Error Messages $\ldots \ldots \ldots \ldots \ldots \ldots \ldots \ldots \ldots \ldots$

Appendix C - Description of PLTWIND Software $\ldots \ldots \ldots \ldots \ldots \ldots \ldots$

Appendix D - Sample PLTWIND Test Cases $\ldots \ldots \ldots \ldots \ldots \ldots \ldots \ldots$ 


\section{Figures}

2.1 Map of the Hanford Site and Surrounding Area $\ldots \ldots \ldots \ldots \ldots \ldots \ldots \ldots$

2.2 Map of Terrain of the Hanford Site and Surrounding Area . . . . . . . . . . . 2.3

2.3 Map of the Meteorology Monitoring Stations on the Hanford Site and in

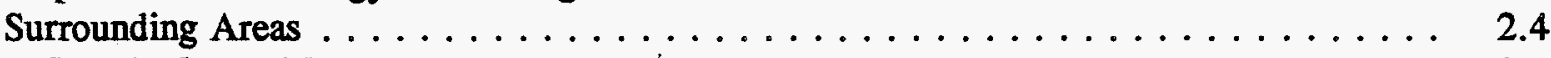

3.1 A Sample Control Menu $\ldots \ldots \ldots \ldots \ldots \ldots \ldots \ldots \ldots \ldots \ldots \ldots \ldots$

3.2 A Sample Plot of Monitored Wind Data with Numerical Output . . . . . . . . . . . . 3.9

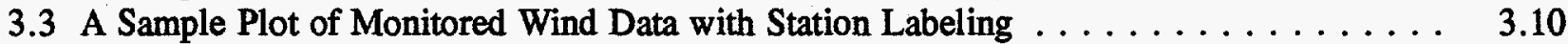

3.4 A Sample Wind Field Plot with Numerical Data $\ldots \ldots \ldots \ldots \ldots \ldots \ldots \ldots \ldots$

3.5 A Sample Wind Field Plot Without Numerical Data . . . . . . . . . . . . . . 3.12

\section{Tables}

2.1 Hanford Wind Monitoring Station Information $\ldots \ldots \ldots \ldots \ldots \ldots \ldots$

3.1 List of Files Required to Run PLTWIND . . . . . . . . . . . . . . . . . . . 3.2

3.2 Comparison of the Times Required to Generate Hardcopy Products . . . . . . . . . . 3.14

\section{Exhibits}

1.1 Summary Procedure for Running PLTWIND $\ldots \ldots \ldots \ldots \ldots \ldots \ldots$

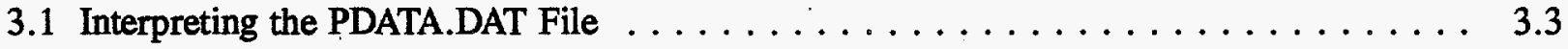

3.2 Instructions for Using an HP LaserJet III Printer to Generate Hardcopies of PLTWIND Graphics $\ldots \ldots \ldots \ldots \ldots \ldots \ldots \ldots \ldots \ldots \ldots \ldots \ldots \ldots \ldots$ 


\subsection{Introduction}

For a variety of emergency response applications, timely and accurate information is needed on the behavior of near-surface winds across the Hanford Site and in neighboring areas. From the early 1980s through 1992, this function was provided by software based on the Unified Dose and Assessment Center's (UDAC's) VAX-11/750 computer and presented using Tektronix monitors and color printers. Over the years, a number of problems in the existing wind field generation software were identified, and the performance of the system's computer hardware no longer met minimum standards. With the VAX computer network's scheduled replacement, an alternative method of supplying wind data to emergency response facilities was required.

To provide an updated system that would utilize the work-station-based computer hardware and software currently in use at Hanford's emergency response facilities, the PLoT Near-Surface WIND (PLTWIND) modeling system has been developed at the Pacific Northwest Laboratory (PNL) ${ }^{(a)}$. Accessing real-time meteorological data provided by the mainframe computer system at the Hanford Meteorology Station and the Hanford Local Area Network (HLAN), the personal-computer-based PLTWIND system processes available data to produce graphical displays of Hanford-area wind measurements and projections of Hanford-area wind fields.

PLTWIND's products are intended for use by emergency response personnel in evaluating atmospheric dispersion characteristics in the near-surface environment. Model products provide important atmospheric information to hazard evaluators; however, these products are only tools for assessing near-surface atmospheric transport and should not be interpreted as providing definitive representation of atmospheric conditions. The user is cautioned to keep in mind that PLTWIND provides only estimates based on data from well-spaced automated monitoring stations that monitor conditions at about $10 \mathrm{~m}$ above groundlevel. The applicability of monitored data to locations between monitoring sites, to elevations more than $10 \mathrm{~m}$ above ground level, and to estimates of future conditions is limited. We emphasize that PLTWIND is intended as a tool to be used by UDAC meteorologists, Hanford Meteorology Station meteorologists, and other emergency response personnel; it is not intended to replace the assessments and forecasts provided by meteorological and atmospheric dispersion assessment personnel on the emergency response team.

\subsection{Hardware and Operating System Requirements for PLTWIND}

PLTWIND is designed to be used with a minimum of training; its user-friendly menu, on-screen instructions, and error-detection modules are geared to assist the inexperienced user in generating model products. However, for PLTWIND to operate correctly, it must be used with the proper hardware and operating system environment. The following hardware is required to operate PLTWIND:

- an IBM-compatible PC with at least VGA graphics capability, and at least a "386" processor (a math coprocessor may be needed for some "386" machines). PLTWIND requires slightly more than 400 kilobytes of memory; some processes (such as some HLAN processes) may have memory.

(a) The Pacific Northwest Laboratory is operated for the U.S. Department of Energy by Battelle Memorial Institute under Contract DE-AC06-76RLO 1830. 
requirements that will not leave the PC sufficient memory to have both PLTWIND and the other processes active at the same time. In such a case, the user may need to obtain expanded or extended memory, utilize a memory management utility, or remove some HLAN products from memory to run PLTWIND.

- a connection to the HLAN to acquire meteorological data files

- an HP-compatible pen plotter or laser printer (with a minimum of 1.5 megabytes of memory and Plotter-in-a-Cartridge hardware). The pen plotter or printer must be attached to the computer's serial port.

PLTWIND is designed to run under the control of a DOS operating system. PLTWIND can be run from WINDOWS after being accessed as a non-Windows application.

\subsection{PLTWIND Operating Sequence}

When PLTWIND is first activated, the model accesses the most recent file of Hanford meteorological data. This file is updated every $15 \mathrm{~min}$ at the Hanford Meteorology Station, copied to the HLAN, and then automatically (on selected systems) transferred by the HLAN to the user's PLTWIND directory. The data file contains information on the monitored winds (i.e., wind direction and speed) at each of Hanford's meteorological monitoring sites and information on other meteorological parameters (e.g., atmospheric stability, mixing depth) monitored at the Hanford Meteorology Station. The file provides data for each 15-min monitoring period extending from about 12 hours in the past up to the most recent observations.

After the meteorological data file is accessed, the model displays the beginning and ending date and time of the available data records. The user must select the date and time of the meteorological data to be processed, select either a plot of observed wind data or a plot of a model-generated wind field, and specify several plotting options.

After performing required model calculations, the model generates the requested wind plot superimposed on a background map of the study region. After the graphical product is displayed on the screen, the user has the option of generating a hardcopy of the graphical product. After each product is displayed or printed, the user has the options of returning to the control menu or exiting the program.

A summary procedure for running PLTWIND is presented in Exhibit 1.1 .

\subsection{Contents of the User's Guide}

In the sections of this User's Guide that follow, we will describe the Hanford Site's environmental setting, provide detailed instructions for using PLTWIND, and provide a short summary of the steps required to run PLTWIND. In the appendices, we will discuss the climate and behavior of winds at the Hanford site, describe PLTWIND top line error messages, discuss how PLTWIND computes wind vectors and wind fields, and present selected test cases. 


\section{Exhibit 1.1. Summary Procedure for Running PLTWIND}

The following procedure is designed as a guide for users experienced in running PLTWIND.

Step 1. Go to the directory into which PLTWIND resides and at the DOS prompt enter:

$>$ PLTWIND <Enter $>$

The PLTWIND control menu will appear on the screen. The up and down arrows on the keyboard are used to move the cursor around the screen. All character or numerical input in the control menu on the must be followed by <Enter $>$ to register the input.

Step 2. The beginning and ending date/times of the available meteorological data available file are displayed on the menu. Data are generally available at 15 -min intervals (beginning on the hour) throughout the data file. Enter the month, day, year, hour of the day, and minutes after the hour for the data record you wish to display.

Step 3. Select your plot option. Press "1" followed by <Enter $>$ to select the plot of monitored wind directions, or press " 2 " followed by <Enter $>$ to select the plot of model-generated wind fields.

Step 4. Select plot options. Press either "Y" or "N" (yes or no) followed by <Enter $>$ to change the value for any option. The following are suggested default values: display full numerical output, make wind vector lengths proportional to the wind speed, and suppress station labeling.

Step 5. After all menu items have been set to the desired value, press $<$ Esc $>$ to generate the wind plot (see Step 6) or $<$ End $>$ to exit the program.

Step 6. Examine the wind plot. To generate a hard copy, press "P". Note that if the computer system is not properly configured to generate the requested hard copy (as described in Section 3.4), a hard copy will not be produced and the user may have to abort the program or reboot the computer to begin again. To look at another plot or to exit the program, press "Q". The plot will be erased and the screen will read "Look at Another?" Press "Y" < Enter> to return to the PLTWIND control menu to prepare another plot (see Step 2) or "N" <Enter > to exit the program. 


\subsection{The Environmental Setting of the Hanford Site}

The Hanford Site is located on approximately $1450 \mathrm{~km}^{2}\left(560 \mathrm{mi}^{2}\right)$ of land in south-central Washington State (Figure 2.1). The topography of the Hanford Site and the surrounding area has a major impact on local winds (Figure 2.2). A variety of terrain is found in this area, including ridges, lower slopes, valley, and river. Ridge terrain is found in the extreme southwestern and western portions of the Hanford Site; lower slope terrain in the southwestern, western, and northern portions of the Site; valley terrain in the central and eastern portions of the Site; and river terrain in the northcentral portion of the Site and along part of the Site's eastern boundary.

The southwestern border of the Hanford Site is marked by the summit ridge of Rattlesnake Mountain. This mountain dominates the area, with an elevation that reaches $1090 \mathrm{~m} \mathrm{(3580} \mathrm{ft})$ above mean sea level. Rattlesnake Mountain and its associated hills extend to the northwest to form the western border of the Hanford Site. The northern boundary of the Hanford Site lies along the lower slope of the Saddle Mountains. These east-west running mountains rise to an elevation of more than $600 \mathrm{~m}(2000 \mathrm{ft})$ above mean sea level.

Northwest of the Site, the Columbia River flows south through a gap in the Saddle Mountains. Near Priest Rapids Dam, the river turns toward the east and flows into the northern portion of the Hanford Site. The river flows east and northeast for about $29 \mathrm{~km}(18 \mathrm{mi})$ before turning toward the southeast. About $35 \mathrm{~km}$ ( $22 \mathrm{mi}$ ) farther downstream, the river turns south and forms the southern half of the eastern boundary of the Hanford Site. The elevation of the terrain to the east of the Hanford Site ranges from 100 to $270 \mathrm{~m}$ ( 340 to $900 \mathrm{ft}$ ) above mean sea level. In places, the bluffs along the eastern shore of the Columbia River rise more than over $150 \mathrm{~m}(500 \mathrm{ft})$ above the surface of the river.

The Hanford Meteorology Station was established in late 1944 to provide a facility for the collection of meteorological data, analysis of meteorological conditions, and preparation of weather forecasts. Continuous observations of hourly meteorological conditions began at the Hanford Meteorology Station on December 7, 1944, and have continued at the same location through the present date. Initially, meteorological observations at the station consisted of wind and temperature data collected at the surface and on the 125-m (410-ft) tower; however, by the end of 1946 the measurement program was expanded to include all of the standard "surface observations" specified by the Weather Bureau. Today, operations at the Hanford Meteorology Station are equivalent to those at a National Weather Service station; data from the station are included in the National Weather Service's automated field station reporting network.

Meteorological monitoring is conducted at the Hanford Meteorology Station and at 26 other automated monitoring sites (Glantz and Islam 1988). These automated monitoring sites consist of three $60-\mathrm{m}(200-\mathrm{ft})$ towers, two $12-\mathrm{m}(40-\mathrm{ft})$ towers with wind sensors mounted at the $9-\mathrm{m}(30-\mathrm{ft})$ level, fourteen 9-m towers with AC-powered instruments, two 9-m towers with battery-powered instruments, radio-tower-mounted instruments in the City of Kennewick, a pole-mounted site on the crest of Rattlesnake Mountain, and two sites on the roof of airport control towers (Glantz and Islam 1988). The approximate locations of the meteorological monitoring sites are shown in Figure 2.3; the names of the monitoring stations are provided in Table $2.1^{(*)}$. Appendix A provides a brief review of the general climate and the characteristic behavior of near-surface winds at Hanford meteorological monitoring locations.

(a) The Benton City Monitoring Station (Station 26) is a new site, as a result it does not appear in any of the sample wind plots presented in this report. 


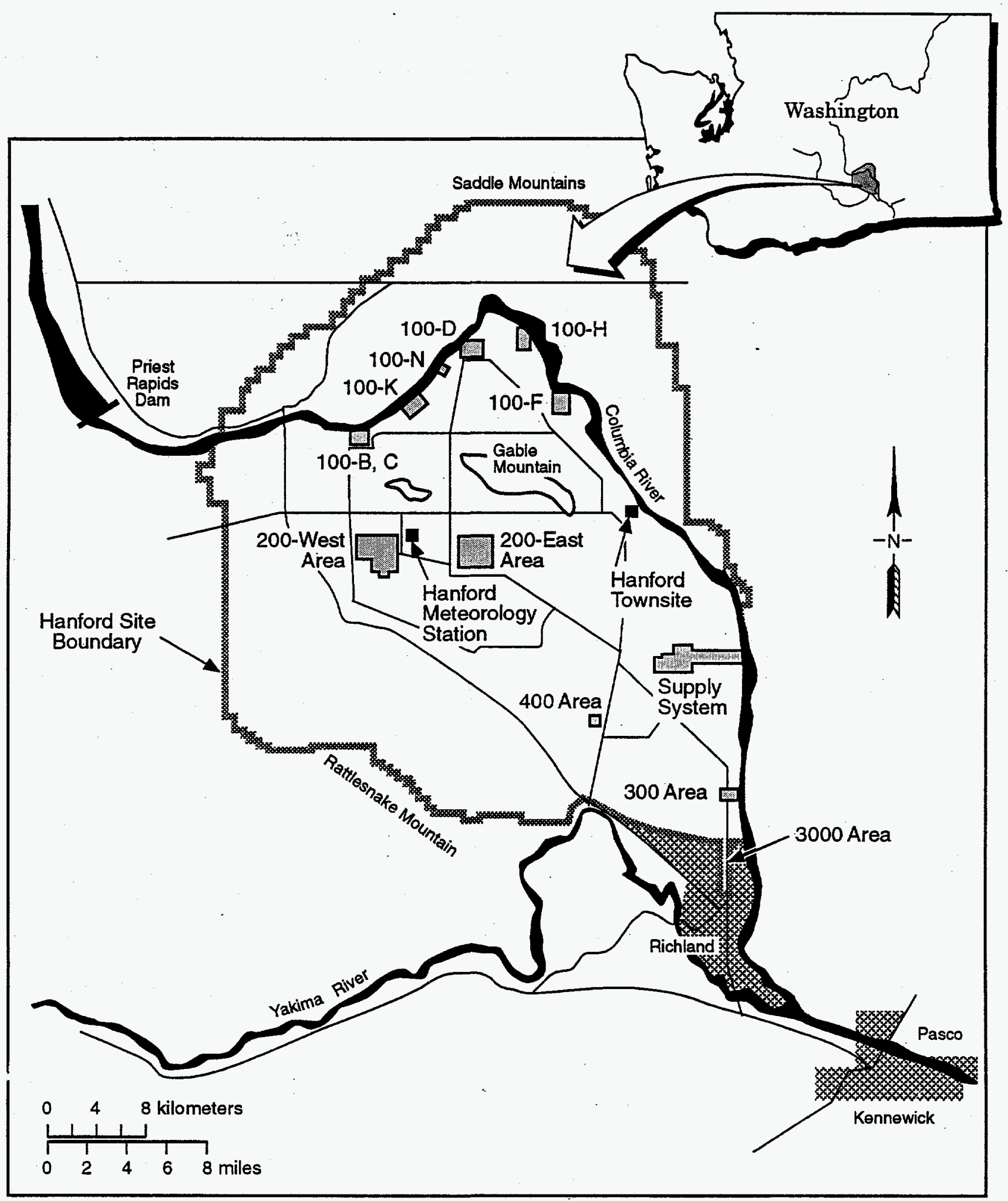

$\$ 9209052.1$

Figure 2.1. Map of the Hanford Site and Surrounding Area 


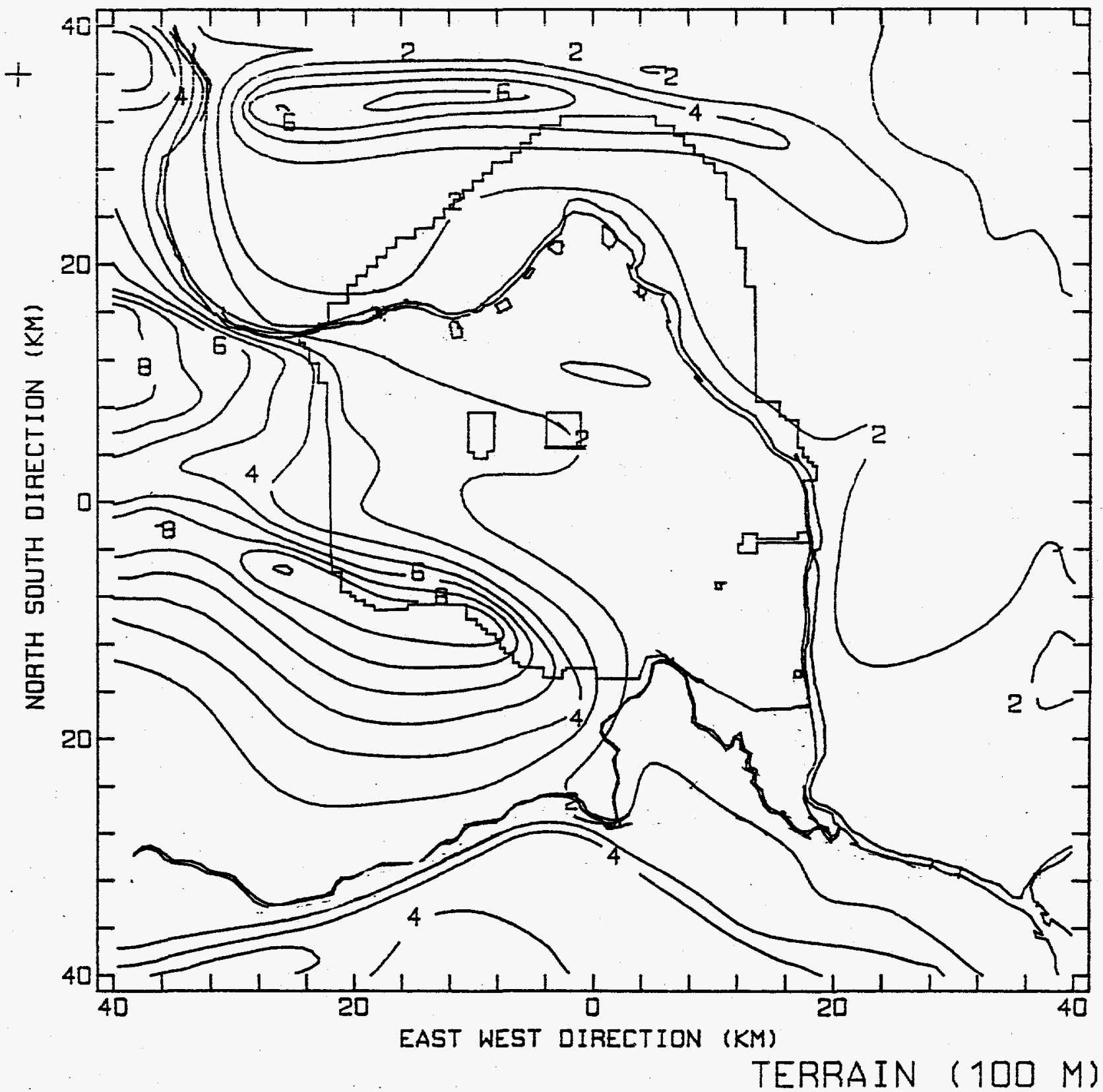

Figure 2.2. Map of Terrain of the Hanford Site and Surrounding Area. The contour lines are labeled by single-digit numbers that represent elevation above sea level in hundreds of meters. Each contour line represents a change in elevation of $200 \mathrm{~m}$ (660 ft). 


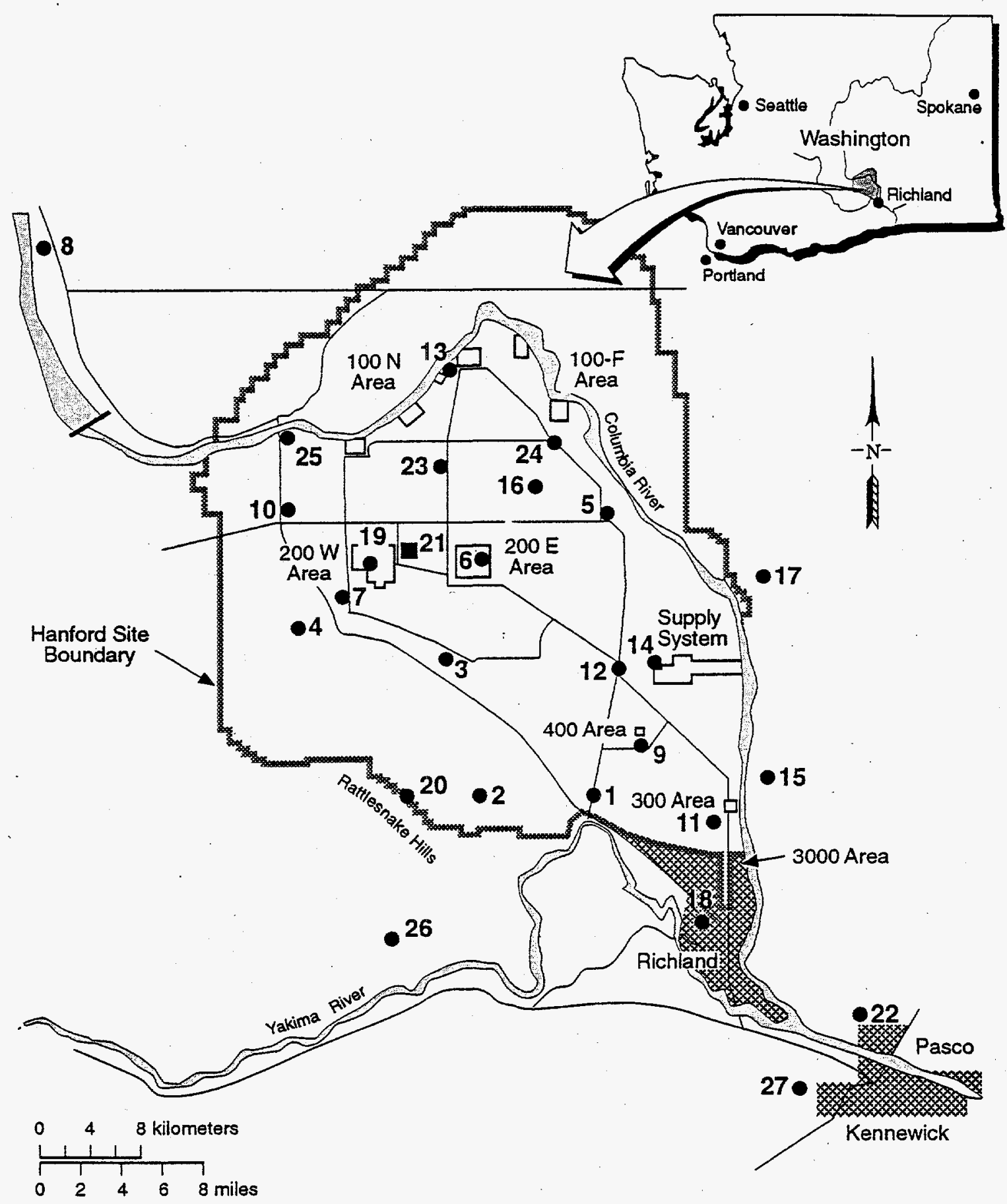

S9406053.1

Figure 2.3. Map of the Meteorology Monitoring Stations on the Hanford Site and in Surrounding Areas. The location of the Hanford Meteorology Station is indicated by a darkened square. Other meteorological monitoring locations are denoted by darkenbed circles. Station identification numbers are plotted alongside the symbols. 
Table 2.1. Hanford Wind Monitoring Station Information. Data are provided on the site ID number, site name, 4-letter site code, east/west and north/south distance from the Site's center (the center is defined as the point at $119.5^{\circ} \mathrm{W}$ longitude and $46.5^{\circ} \mathrm{N}$ latitude), and the elevation above mean sea level at the base of each monitoring station. For the east/west distances, positive numbers are east of $119.5^{\circ} \mathrm{W}$ longitude and negative numbers are west. For the north/south distances, positive numbers are north of $46.5^{\circ} \mathrm{N}$ latitude and negative numbers are south.

\begin{tabular}{|c|c|c|c|c|c|}
\hline \multirow[b]{2}{*}{ Site ID } & \multirow[b]{2}{*}{ Site Name } & \multirow[b]{2}{*}{ Site Code } & \multicolumn{2}{|c|}{$\begin{array}{l}\text { Distance from Site Center, } \\
\text { km }\end{array}$} & \multirow{2}{*}{$\begin{array}{c}\text { Elevation } \\
\text { above sea } \\
\text { level, m }\end{array}$} \\
\hline & & & $E / W$ & $\mathbf{N} / \mathbf{S}$ & \\
\hline 1 & Prosser Barricade & PROS & 6.83 & -12.01 & 146 \\
\hline 2 & Emergency Operations Center & EOC & -2.78 & -11.94 & 378 \\
\hline 3 & Army Loop Road & ARMY & -3.69 & -1.27 & 172 \\
\hline 4 & Rattlesnake Springs & RSPG & -15.26 & .70 & 207 \\
\hline 5 & Edna Railroad Crossing & EDNA & 7.88 & 9.73 & 122 \\
\hline 6 & 200 East Area & $200 \mathrm{E}$ & -1.58 & 6.27 & 204 \\
\hline 7 & 200 West Area & $200 W$ & -12.78 & 4.49 & 201 \\
\hline 8 & Beverly & BVLY & -33.09 & 28.47 & 154 \\
\hline 9 & Fast Flux Test Facility & FFTF & 10.86 & -7.73 & 168 \\
\hline 10 & Yakima Barricade & YAKB & -17.24 & 8.70 & 242 \\
\hline 11 & 300 Area & $300 \mathrm{~A}$ & 16.49 & -15.10 & 122 \\
\hline 12 & Wye Barricade & WYEB & 8.23 & -1.97 & 168 \\
\hline 13 & $100 \mathrm{~N}$ Area & $100 \mathrm{~N}$ & -3.78 & 20.86 & 146 \\
\hline 14 & Wash. Nuclear Power Plant \#2 & WPPS & 12.07 & -3.32 & 137 \\
\hline 15 & Franklin County & FRNK & 20.23 & -9.13 & 268 \\
\hline 16 & Gable Mountain & GABL & 3.06 & 10.90 & 331 \\
\hline 17 & Ringold & RING & 20.17 & 5.03 & 189 \\
\hline 18 & Richland Airport & RICH & 15.38 & -22.08 & 119 \\
\hline 19 & Plutonium Finishing Plant & PFP & -9.70 & 5.30 & 215 \\
\hline 20 & Rattlesnake Mountain & RMTN & -7.20 & -11.73 & 1087 \\
\hline 21 & Hanford Meteorology Station & HMS & -7.53 & 6.98 & 222 \\
\hline 22 & Pasco Airport & PASC & 29.67 & -26.23 & 122 \\
\hline 23 & Gable West & GABW & -4.32 & 12.19 & 150 \\
\hline 24 & 100 F Area & $100 \mathrm{~F}$ & 3.74 & 15.00 & 125 \\
\hline 25 & Vernita Bridge & VERN & -17.18 & 16.13 & 131 \\
\hline 26 & Benton City & BENT & -13.00 & -24.00 & 320 \\
\hline 27 & Vista Field (Kennewick) & VSTA & 21.70 & -31.20 & 120 \\
\hline
\end{tabular}




\subsection{Instructions on How to Use PLTWIND}

To run PLTWIND, the program directory must contain an executable version of PLTWIND and associated station data and graphics files. Table 3.1 contains a list of these files. In addition, a meteorological data file must be accessible in the computer's HUDU directory.

Generating PLTWIND products can be thought of as a four-step process. These steps are to

1) acquire the most recent meteorological data

2) specify the desired graphical product

3) generate the desired graphical product

4) generate a hardcopy of the graphical product.

Before proceeding with these steps, the user must first start PLTWIND. To do this, enter the command PLTWIND < Enter> at the DOS prompt. If the message - "Program too big to fit in memory" appears on the screen, it indicates that too much system memory is already reserved for other ongoing processes (e.g., the HLAN) for PLTWIND to run. To correct this problem, the user must create more system memory. This may involve temporarily stopping other system processes to free up more memory or employing a memory management utility. Because PLTWIND relies on the HLAN to provide real-time meteorological data, the entire HLAN cannot be removed from the user's system to free up additional memory. If this problem occurs, the user may wish to consult the UDAC system manager for information on how to set up a functional computer system environment for PLTWIND.

If a series of "garbage" characters, interspaced with menu text lines, appears on the screen as PLTWIND begins to run, it indicates that the user's system is not recognizing the program's ANSI character set commands. This can be corrected by adding the following line in the user's C:ICONFIG.SYS file and rebooting the system (the CONFIG:SYS file is processed as part of the computer's standard power-up procedure or when manually "rebooted"):

\section{DEVICE $=\mathrm{C}:$ IDOS $\backslash A N S I . S Y S$}

This line instructs the computer to use the DOS operating system's ANSI.SYS file. This file should be installed as part of the user's "DOS" directory. If it is not, contact the UDAC system manager for guidance. The ANSI.SYS file must be on the user's system and its presence must be defined in the user's CONFIG.SYS file.

\subsection{Acquiring Meteorological Data File}

To provide useful information, PLTWIND must acquire timely data on meteorological conditions at wind monitoring stations. Every $15 \mathrm{~min}$, data on winds, temperatures, and other meteorological parameters are transmitted from Hanford's automated monitoring stations to the system computer at the Hanford Meteorology Station. These meteorological data represent averages for the previous 15 min 
Table 3.1. List of Files Required to Run PLTWIND

\begin{tabular}{|l|l||}
\hline \multicolumn{1}{|c|}{ Name of File } & \multicolumn{1}{c|}{ Purpose of File } \\
\hline \hline PLTWIND.EXE & Executable version of the PLTWIND program. \\
\hline PLTWIND.DEF & $\begin{array}{l}\text { Optional default file containing user's last menu selections. This file is } \\
\text { automatically created by PLTWIND.EXE if the file does not exist in the } \\
\text { program's directory. }\end{array}$ \\
\hline CENTIMG.DAT & $\begin{array}{l}\text { Data file containing the background Hanford map for the screen display of } \\
\text { PLTWIND output. }\end{array}$ \\
\hline CENTHPF.DAT & $\begin{array}{l}\text { Data file containing the background Hanford map for hardcopy prints of } \\
\text { PLTWIND output. }\end{array}$ \\
\hline CENTSTA.DAT & $\begin{array}{l}\text { Data file containing the name, location, and elevation of wind monitoring } \\
\text { stations. }\end{array}$ \\
\hline
\end{tabular}

of observations. The data and time used to label each meteorological data record represent the ending date and time for the record's averaging period. The process of acquiring the meteorological data from each monitoring station, running quality assurance checks on the data, and copying the data to the HLAN takes about $20 \mathrm{~min}$. Therefore, each new data record is about $20 \mathrm{~min}$ old when it arrives at a user's computer (i.e., the newest data arrive $20 \mathrm{~min}$ after the completion of the indicated monitoring period). For example, data representative of conditions between 10:00 and 10:15 are labeled with the time "10:15" and on average would become available to users through the HLAN at about 10:35. When this data record arrives, data for the next averaging period (10:30) are already being collected and processed at the Hanford Meteorology Station.

The meteorological data file from the Hanford Meteorology Station is named "PDATA.DAT." Every $15 \mathrm{~min}$, the HLAN automatically updates the PDATA.DAT on the computer systems of designated emergency response users. This data file overwrites the previous version of PDATA.DAT. Once it is in a user's directory, PLTWIND will automatically access the new file whenever it is requested to generate a wind plot or update PLTWIND's control menu.

Each PDATA.DAT file contains 48 data records; this is equivalent to about $12 \mathrm{~h}$ of meteorological data. The PDATA.DAT file is a standard formatted file, with each data record containing three lines of data. The structure of a data record is presented in Exhibit 3.1.

\subsection{Specifying the Desired Graphical Product}

The second step in the use of PLTWIND is to specify the desired screen display of wind vectors or wind fields. After activation, PLTWIND will display its user control menu (Figure 3.1). 
Exhibit 3.1. Interpreting the PDATA.DAT File. Data records are provided for April 11, 1995 (Julian day 101), at 9:45 and 10:00. Each data record contains three lines of data to provide information for up to 30 meteorological monitoring sites. Each line provides the year, day of year, hour, minute, data record line number, stability class, and mixing height (in tens of meters); this is followed by the wind direction (in tens of degrees) and wind speed (mph) for ten monitoring stations.

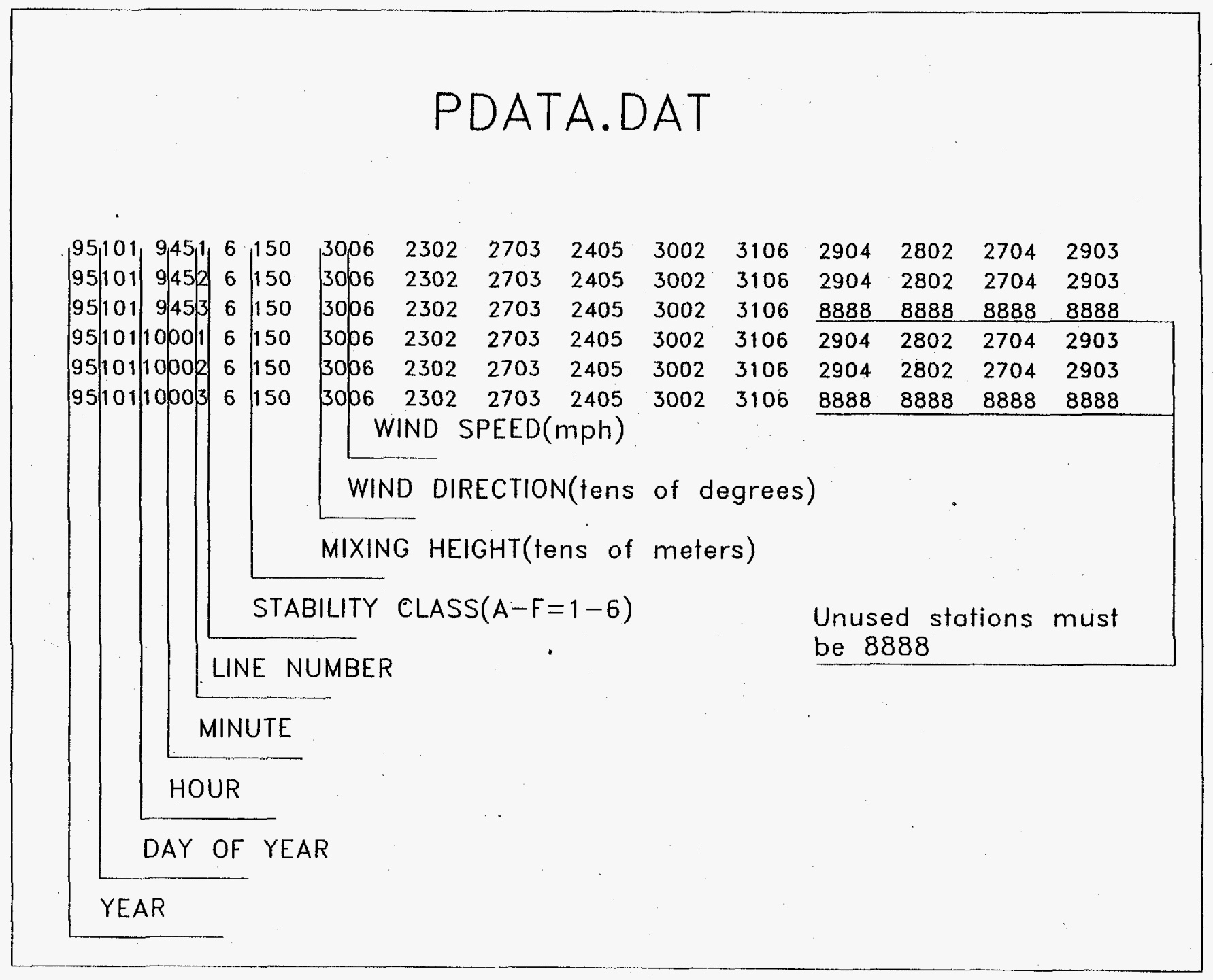




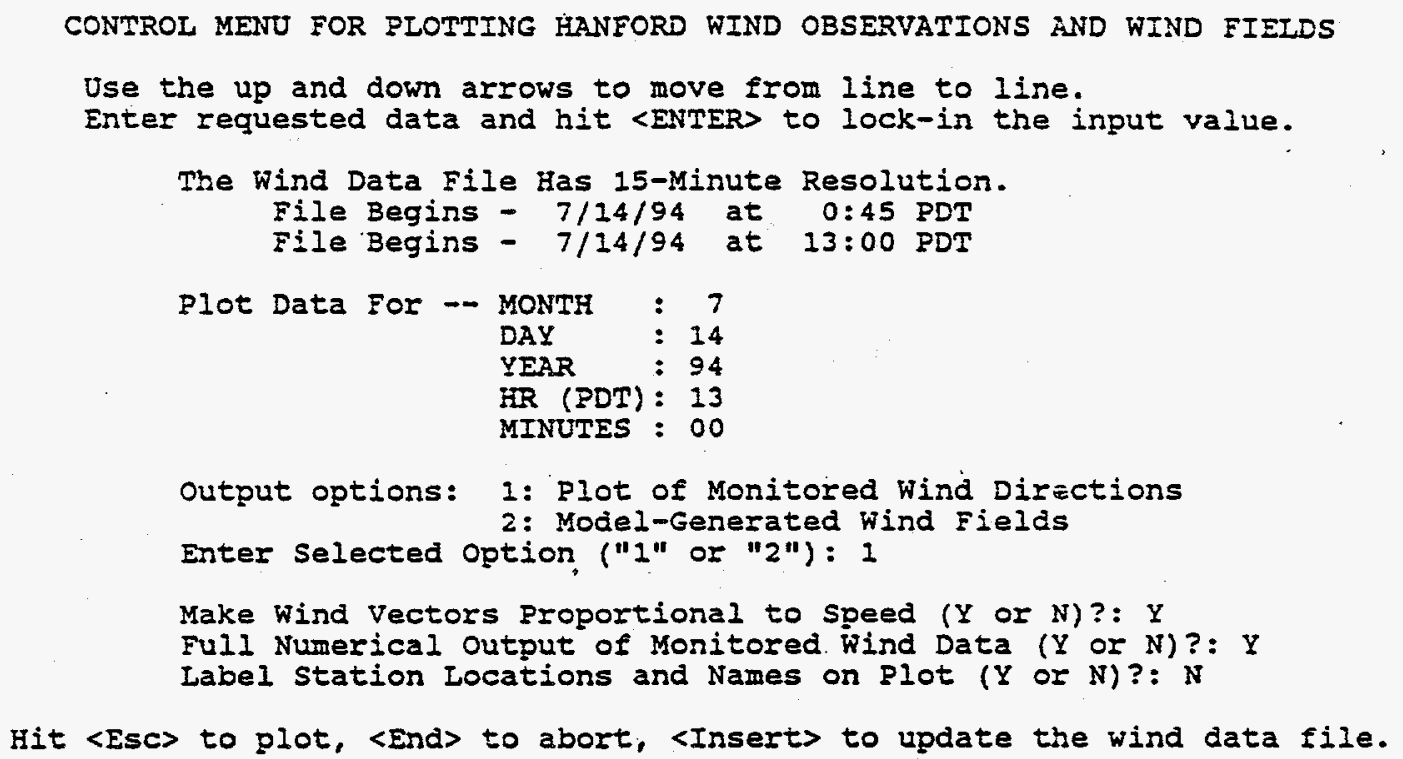

Figure 3.1. A Sample Control Menu

\subsubsection{Layout of the Control Menu}

The control menu displays the following information:

- the time resolution of the wind data file (i.e., 15-min or hourly)

- the date/time of the first and last data records in the data file

- the user-specified date/time of the data selected for plotting (the default value is initially the most recent data record in the file and later becomes the last record selected for plotting)

- a user-specified selection of whether to plot monitored wind vectors or the model-generated wind field

- user-specified output options to make wind vectors proportional to wind speed, to provide full numerical output in the plot margins, and to label the wind stations.

Just before PLTWIND begins executing a new plot and just before the program is terminated, userspecified output options are stored in a default file (named PLTWIND.DEF) so that the most recent user selections can be returned to the screen after the completion of a plot or on restarting the program. The user need not be concerned with the default file; it is automatically accessed and updated by the model and a new default file is automatically created if the default file has been deleted from the program's directory. 


\subsubsection{Moving Around the Control Menu}

To move from item to item on the control menu, the user positions the cursor using the up and down arrows on the keyboard. Any value to be entered onto the menu must be followed by the <Enter > key. The <Enter > key is used to confirm that a change in a menu parameter should be implemented. Although newly entered data will appear on the screen, the program does not erase an earlier entry from its memory and accept the new input until the <Enter $>$ key is pressed.

\subsubsection{Selecting a Date/Time for Plotting}

The first series of input lines allows the user to enter the month, day, year, hour, and minute of the meteorological data record to be examined. All dates and times must be specified using one- or twodigit integer values (followed by $<$ Enter $>$ ). Values outside the time limits imposed by the first and last records of the meteorological data file, values that do not correspond to a valid date/time, and noninteger inputs will not be accepted. Times are given in Pacific Standard Time (PST) or Pacific Daylight Time (PDT), depending on the time of the year. During the one-week periods in the spring and fall when the transition to daylight and standard time, respectively, may occur, time will be reported in PST with the message "add $1 \mathrm{~h}$ for PDT".

\subsubsection{Selecting the Type of Plot}

The user can choose one of two output options - a plot of monitored winds or a plot of a modelgenerated wind field. These options are selected by user input of the integers " 1 " or " 2 " (followed by $<$ Enter $>$ ); a plot cannot be generated unless one of these two values is specified.

An input value of " 1 " selects a plot of monitored winds data. This product uses wind vectors to graphically indicate the direction of the observed wind at each monitoring station. Wind vectors are superimposed on a background map of the Hanford Site and the surrounding region. Each vector points in the direction to which the wind is blowing at the monitoring station. Each vector is drawn so that its "midpoint" represents the position of its monitoring station (the midpoint is halfway between the vector's tail and arrow tip). Wind speed may also be indicated by the vector. If the wind speed option is chosen (see below), the size of the wind vectors is proportional to their wind speeds.

An input value of "2" selects a plot of the model-generated wind field. The wind field plot uses observed data to estimate wind directions and speeds at each grid point on a 21 by 21 modeling domain (441 grid points) that covers an area of $80 \mathrm{~km}$ by $80 \mathrm{~km}\left(6,400 \mathrm{~km}^{2}\right)$. As in the plot of monitored winds, each vector points in the direction toward which the wind is blowing and the vector's "midpoint" represents the position of its grid point. Wind speed may also be indicated by the vector. Wind vectors are superimposed on a background map of the Hanford Site and surrounding region. The wind field plot is based on an algorithm developed for the MESOI (Ramsdell et al. 1983) and MESORAD (Scherpelz et al. 1986; Ramsdell et al. 1988) atmospheric dispersion models. The algorithm used to plot the wind field and limitations on the use of this product are discussed in Appendix C.

\subsubsection{Selecting Plot Options}

The final three options on the control menu allow the user to modify the output product. An option is turned on by inputting a " $\mathrm{Y}$ " value and shut off by inputting a " $\mathrm{N}$ " value (either value must be 
followed by $<$ Enter $>$ ). The first of these options allows the user to choose either to have wind direction vectors be proportional to wind speed (to graphically display wind speed information) or to have all wind vectors drawn the same size (independent of the reported wind speed).

The second option allows the user to have the full numerical output of monitoring station information plotted in the right margin of the wind plot. This numerical information includes each monitoring station's four-character code name, the wind direction (the direction from which the wind is blowing in ${ }^{\circ}$ from $\mathrm{N}$ ), and wind speed (in mph). Stations located above $300 \mathrm{~m}$ above sea level (about 1,000 ft) are indicated with an asterisk. These stations tend to be characterized by greater wind speeds because of their elevation above most of the region's lower-lying topography.

The last option is designed for use with the plot of monitored winds to assist the user in relating graphical and numerical data (note that this option cannot be used with the plot of the model-generated wind field). When this option is activated, each wind monitoring station's four-character code designation is plotted behind an " $x$ " that designates that station's approximate location on the background map. Because this option can create a cluttered product, it is recommended that its use be limited.

For each of the three output options, input values of " $\mathrm{Y}$ " or "N" must appear on the menu. No plot will be generated if an incorrect value appears for an output option.

\subsubsection{Executing Products, Accessing an Updated Meteorology File, and Exiting the Model}

After all user options are specified, the user may begin generating the requested plot by pressing the <Esc > key, which is located near the upper left corner of the standard PC keyboard. This key was selected to be the program's "execute" key because of its easily identifiable position in the extreme upper left corner of the keyboard. Because this key has no immediate neighbors, a user will be less likely to accidentally depress another key when reaching for the $<$ Esc $>$ key. If a user hits the $\langle$ Esc $>$ key without the control menu being completed, one of two things may occur. The program may terminate with an error message or the model may run using the immediately previous input values (which are no longer displayed). If the model terminates inadvertently, the user can restart PLTWIND and try again. If the user does not want to attempt another plot after an inadvertent termination, PLTWIND should be restarted and promptly exited (to ensure that the computer returns to the proper graphics mode).

Although the most recent meteorological data file is always accessed by PLTWIND, the beginning and ending date/time of the file are only updated when PLTWIND is first accessed, when a plot is completed and the user requests a return to the control menu (i.e., when the user responds affirmatively to the question "Look at Another?"), and when the user manually refreshes the control menu. To manually refresh the control menu, the user must press the <Insert $>$ key located toward the upper right position on the standard PC keyboard. Selecting this option causes the program to read the current PDATA.DAT file and determine the beginning and ending date/times of the data. If PDATA.DAT has not been updated since the control menu was brought up on the screen, no change will occur. If PDATA.DAT has been updated, the new beginning and ending date/times of the file will be displayed on the screen. The user may then wish to focus attention on the record with the most recent meteorological data. 
To terminate the PLTWIND session, the user should press the <End $>$ key. This key is generally located to the right and slightly above the $<$ Enter $>$ key. When the $<$ End $>$ key is pressed from the control menu, the program will terminate.

\subsubsection{Error Detection During the Input of Parameters}

The PLTWIND program is coded to detect certain types of user input errors and to notify the user of these errors. When an error occurs, a highlighted message is written on the top line of the control menu. The user can press any key to delete the message and return the cursor to the line at which the error was made. In Appendix B, we briefly discuss the error messages that PLTWIND could display on the top line of the control menu, report likely causes of the error, and suggests methods for correcting the problem.

As stated above, a plot cannot be generated if an incorrect value has been entered without being corrected by the user before a plot of a wind product is requested.

\subsection{Generating a Graphical Product}

After a graphical product is requested by pressing the <Esc $>$ key, the computer will immediately begin to plot the graphical product. On a 486-based PC with a 66-MHz clock speed, it takes about a second after the <Esc > key is pressed before the computer screen goes blank and the program begins to plot the output product. The sequence in which portions of the product appear on the screen is as follows: Hanford Site background map, plot frame, headings, wind plot data, and, if requested, numerical information in the right margin. It takes only a few seconds to complete a plot of monitored wind data and a few extra seconds to complete a wind field plot. The additional time for a wind field plot is due in part to the time it takes to set up the wind field grid and compute the winds at each model grid point.

Figure 3.2 presents a standard plot of monitored winds. In all plots, the date and time are denoted in the upper right corner of the plot. The "CENT" label in the lower left corner of the plot indicates that the background map of the Hanford Site is centered at the approximate center of the Site (i.e., $119.5^{\circ} \mathrm{W}, 46.5^{\circ} \mathrm{N}$ ). The axes of the plot indicate distance in kilometers from the center. Tick marks on each axis are placed at 4-km intervals; this corresponds to the spacing between grid points on the 21 by 21 modeling domain. Beneath the main title under each plot, a second heading indicates whether wind vectors are drawn with their length proportional to the wind speed.

The title beneath all plots of monitored winds states that data are based on observations made by sensors located approximately $10 \mathrm{~m}$ above ground level at each monitoring station. In the lower right corner of the plot, the observed atmospheric stability is given using the Pasquill-Gifford letter category. ${ }^{(a)}$

(a) In this categorization scheme, atmospheric stability classes are " $A$ " (highly unstable), "B" (moderately unstable), "C" (slightly unstable), "D" (neutral), "E" (slightly stable), "F" (moderately stable), and " $G$ " (extremely stable). Generally, the more unstable the atmosphere the greater the rate of lateral and vertical spreading of pollutant material. 
In Figure 3.2, wind vectors are drawn proportional to the wind speed and numerical data on the winds at the monitoring stations are provided in the right margin. In Figure 3.3, the same data are plotted but wind vectors are drawn with their size not proportional to the wind speed. Also, in Figure 3.3, the option to label wind station locations is enabled and the approximate station locations are plotted on the background map.

Figure 3.4 presents a standard plot of wind field data. The title beneath all wind field plots states that the data presented are a gridded plot of near-surface winds (winds at $10 \mathrm{~m}$ above ground level). In the lower right corner of the plot, the maximum wind speed on the modeling domain is presented. In Figure 3.4, wind vectors at each grid point are drawn proportional to the wind speed, and numerical data on the winds at the monitoring stations are provided in the right margin. In Figure 3.5, the same data are plotted but the size of the wind vectors is not proportional to the wind speed and numerical data are not provided.

After a wind plot is successfully displayed on the screen, a message will appear on the top line offering the user the option of generating a hardcopy of the graphical product or quitting the display. The user may examine the screen for any length of time without selecting an option. Pressing "P" (for print) will start the program generating a hardcopy of the graphical product; an input of " $Q$ " (for quit) will erase the plot and the question "Look at Another?" will appear on the screen. A response of " $Y$ " to this query returns the user to the main control menu; a response of " $\mathrm{N}^{\prime \prime}$ terminates the PLTWIND session.

\subsection{Generating a Hardcopy of the Graphical Product}

If the user chooses to generate a hardcopy of the graphical product, by pressing "P" in response to the message on the top line of the plot, the screen will dim and the keyboard will temporarily lock-up as a hardcopy product is created. To generate a hardcopy of the screen, the user's system must have the required laser printer, plotting cartridge, and cable connections. A lack of the required hardware may result in the keyboard lock-up persisting until the user reboots the computer to restore normal system operation. Exhibit 3.2 provides instructions on how to configure an HP printer for generating hardcopy graphical output.

The more written information that is contained in a particular plot, the longer it will take for the hardcopy product to be produced. Tested on a 486-based $\mathrm{PC}$ with a $66-\mathrm{MHz}$ clock speed, a simple plot of monitored wind data without any numerical information will lock-up the keyboard for about $75 \mathrm{~s}$ and it will take an additional $30 \mathrm{~s}$ to complete outputting the product. A complete wind field plot with full numerical output in the right margin will lock-up the keyboard for about $150 \mathrm{~s}$ and it will take an additional $30 \mathrm{~s}$ to complete outputting the product. Table 3.2 presents information on the relative plotting times of different products.

A series of four pens are used to generate portions of each plot. On the screen these pens are assigned different colors; on the laser printer the pens can be set to different thicknesses. By adjusting the laser printer's pen thicknesses (using the printer's menu button with the printer in the HPplotter mode), wind vectors and numerical output can be highlighted using thicker lines and characters. Specific instructions on how to set pen thicknesses on the laser printer are provided in the user's guide for the printer. 

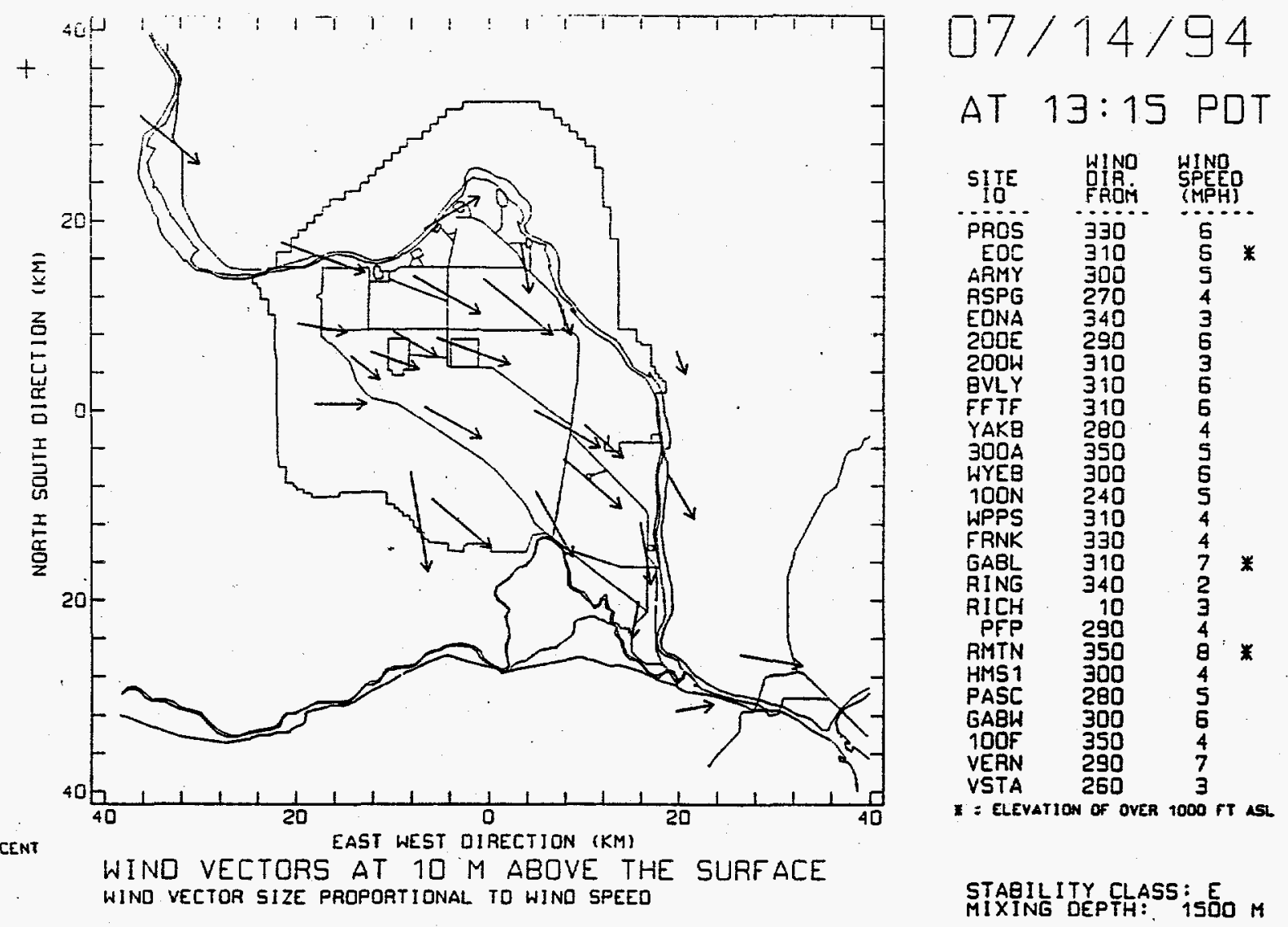

Figure 3.2. A Sample Plot of Monitored Wind Data with Numerical Output. Wind vector length is proportional to wind-speed. 

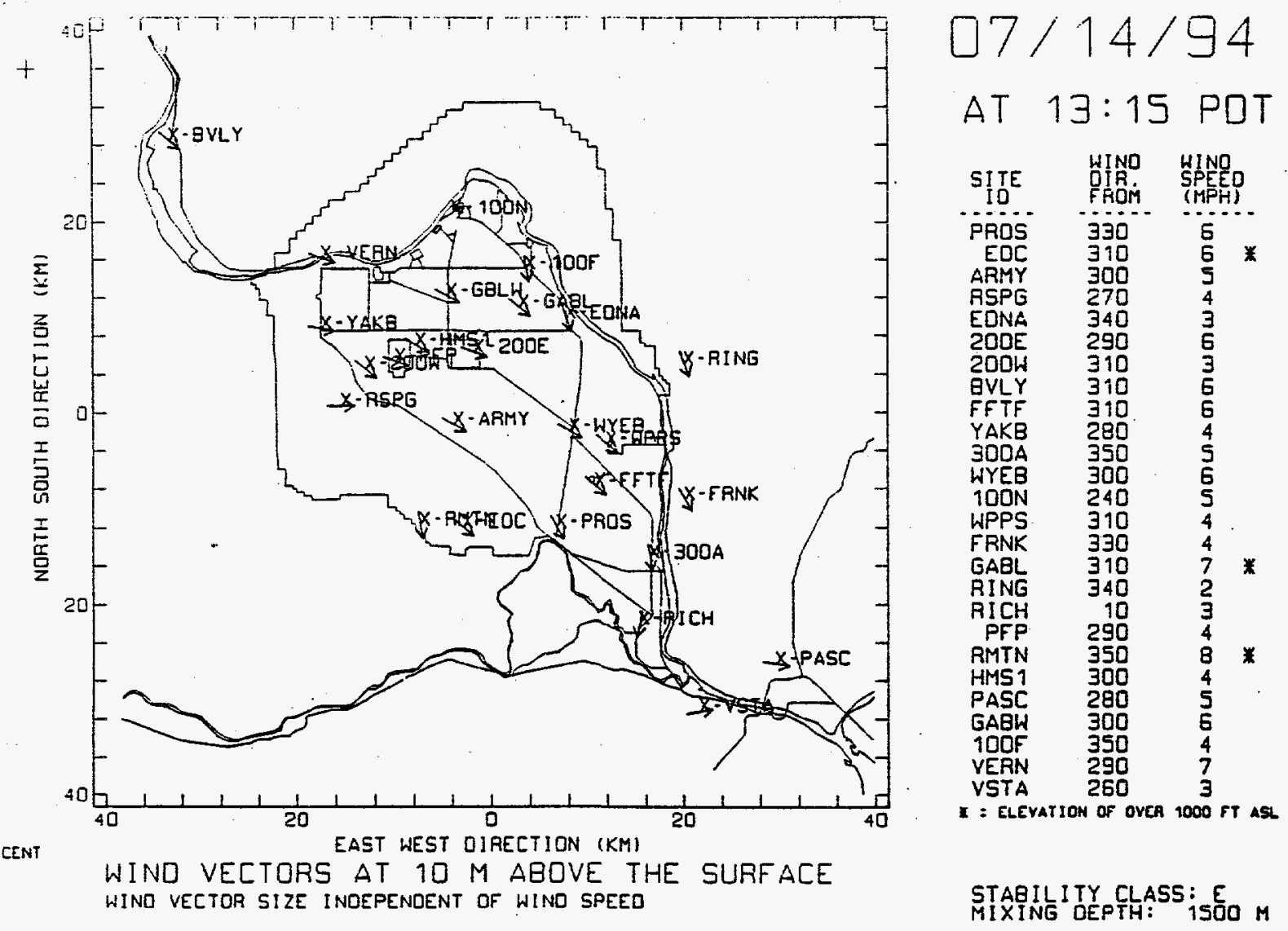

Figure 3.3. A Sample Plot of Monitored Wind Data with Station Labeling. Wind vector length is independent of wind speed. 


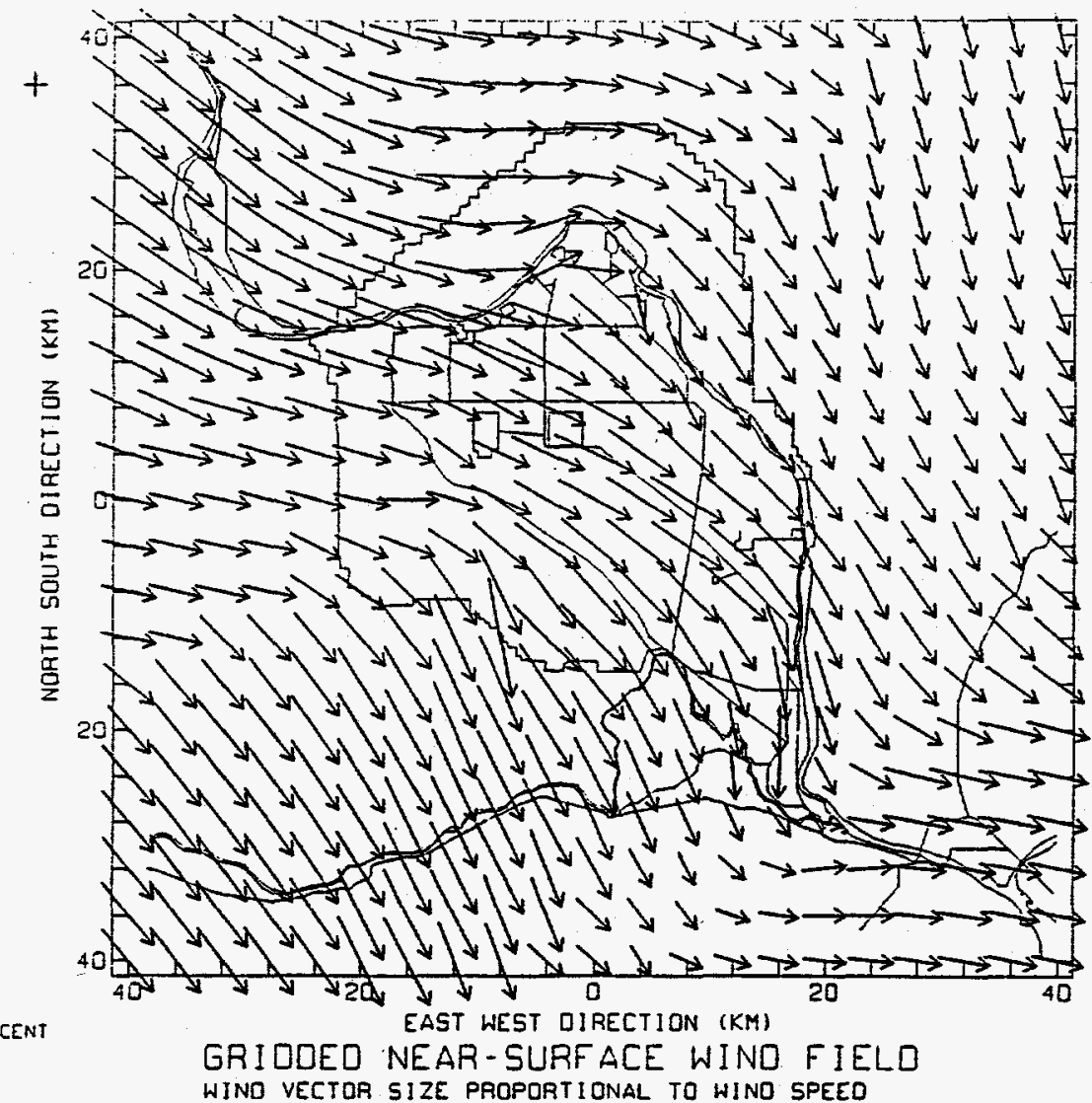

$07 / 14 / 94$

AT 13:15 PDT

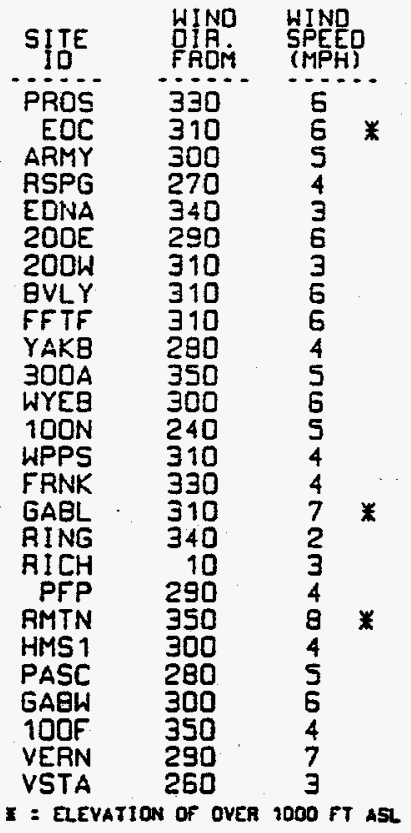

MAX. HIND SPO: OB MPH

Figure 3.4. A Sample Wind Field Plot with Numerical Data. Wind vector length is proportional to wind speed. 


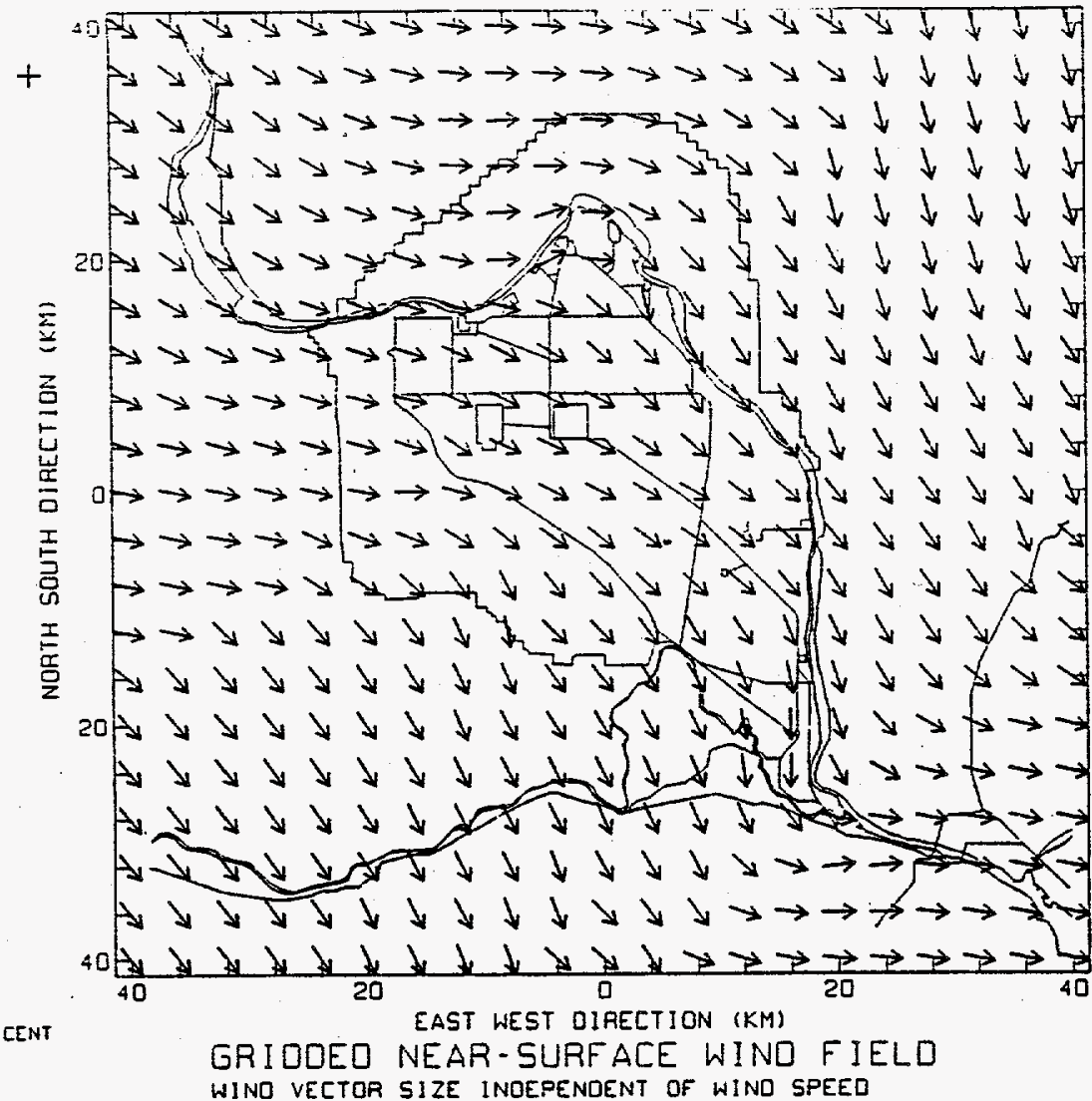

$07 / 14 / 94$

AT 13:15 POT

Figure 3.5. A Sample Wind Field Plot Without Numerical Data. Wind vector length is independent of wind speed. 


\section{Exhibit 3.2. Instructions for Using an HP LaserJet III Printer to Generate Hardcopies of PLTWIND Graphics}

Plotting output goes to the HP printer through the COM1 serial port on the computer. To print to the HP printer you must have:

- proper hardware and memory

- "Plotter-in-a-Cartridge" hardware

- a serial connection from the computer's COM1 port to the serial input on the back of the HP printer.

With the "Plotter-in-a-Cartridge" inserted into the left cartridge slot on an HP Laser Jet printer (with a minimum of 1.5 megabytes of memory), the printer display should read "HP7475 Plotter" mode.

\section{Setting the Printer to Accept Input from the Serial Port}

Press the "On Line" key to turn the printer off-line, hold "Menu" key for about 8 seconds. When the "Port Select" option appears in the window, press the "Enter" key on the printer. Press the " + " or " - key until the word "All" appears in the window, press "Enter" again and make sure that a "\#" sign appears on the right side of the window. This indicates that the printer is now configured to accept input form either the serial or parallel ports. Press "On Line" to save changes and return to on-line status.

\section{Setting Pen Widths}

Press the "On Line" key to turn the printer off-line and quickly press and release the "Menu" key. When the "Pen Carousel" option appears in the window, press the "Enter" key. Data for Pen 1 will appear in the window. Set Pen 1 to 1 dot by

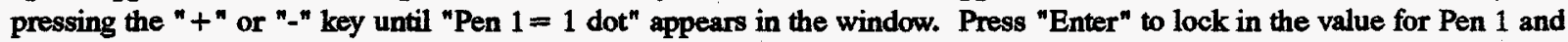
then set Pen 2 to 1 dot by pressing the " + " or "-" key until "Pen $2=1$ dot" appears in the window. Repeat for Pen 3 . For Pen 4, set the value to "Pen $4=3 \operatorname{dot}^{n}$. This sets the pen widths to appropriate values for the black-and-white wind plots. Press "On Line" to save changes and return to on-line status.

\section{Setting Page Eject and Obtaining a Hardcopy Plot}

Press the "On Line" key to turn the printer off-line and quickly press and release the "Menu" key. Press and release the " + " key until "Autopageeject" appears in the window. Press "Enter". Press the " + "key to display "Disab." in the window. Press "Enter" to make sure that a "\#" sign appears on the extreme right side of the window. This indicates that the printer is now configured so that it will not automatically eject printed pages; this allows PLTWIND to superimpose wind plots on top of the appropriate background map. Press "On Line" to save changes and return to on-line status.

To obtain a hardcopy plot, the user must now hit "Form Feed" when the printer is on-line (not off-line), after output is done being copied to the printer, to obtain a hard copy plot of the output product. 
Table 3.2. Comparison of the Times Required to Generate Hardcopy Products. Values are for trials with a 486-based PC (66-MHz clock speed). The time is measured in minutes and seconds from the time the hardcopy option (i.e., "P") is selected. Actual times may vary depending on the characteristics of the hardware employed on individual systems.

\begin{tabular}{||l|c|c||}
\hline \multicolumn{1}{|c|}{ Product Description } & \multicolumn{2}{c|}{ Total Time (min:s) } \\
\hline \hline Monitored wind data without numerical output & $\begin{array}{c}\text { Keyboard } \\
\text { Lock-up }\end{array}$ & $\begin{array}{c}\text { Complete } \\
\text { Hardcopy }\end{array}$ \\
\hline Monitored wind data with numerical output & $1: 15$ & $1: 45$ \\
\hline Wind field data without numerical output & $1: 40$ & $2: 15$ \\
\hline Wind field data wind data with numerical output & $2: 30$ & $3: 00$ \\
\hline
\end{tabular}




\subsection{Summary of Key Instructions for PLTWIND}

The following provides summary instructions for running PLTWIND on computer systems designated for emergency response users on the HLAN. These instructions are presented as a guide for experienced PLTWIND users.

Set the Computer to the Directory That Contains PLTWIND.

The PLTWIND directory must contain the executable version of the PLTWIND code, a meteorological data file (that will be updated), and associated station data and graphics files. A full list of these files are presented in Table 3.1.

\section{Start PLTWIND.}

At the DOS prompt, type "PLTWIND" and press <Enter >. If the PLTWIND control menu does not appear on the screen, a problem exists. See Section 3.0 for a discussion of potential problems and remedies. To move around the control menu, use the up and down arrow keys. Instructions for inputting data and generating plots are provided on the control menu screen.

\section{Meteorologic Data Files are Automatically Updated.}

At 15-min intervals, meteorologic data are automatically acquired from monitoring stations, processed at the weather station computer, copied to the HLAN, and copied to the PDATA.DAT file in the designated computer's PLTWIND directory. Because of processing and data transmission requirements, note that it takes about $20 \mathrm{~min}$ for a data entry to reach the user's computers. Once the data are copied from the HLAN, PLTWIND will automatically access the new file whenever it is requested to generate a wind plot or update PLTWIND's control menu (press <Insert $>$ to update the control menu without making any changes).

\section{Specify the Date/Time for the Data to be Plotted.}

Specify the month, day, year, hour, and minute of the meteorological data record to be examined. When a new PDATA.DAT file is available, the time/date specified must be manually entered to plot the most recent data record. All dates and times must be specified using one- or two-digit integer values (followed by $<$ Enter $>$ ). Values outside the time limits imposed by the first and last records of the meteorological data file will not be accepted. Times are given in Pacific Standard Time (PST) or Pacific Daylight Time (PDT), depending on the time of the year.

\section{Specify the Type of Plot.}

Choose one of two output options - a plot of monitored winds or a plot of a model-generated wind field. These options are selected by user input of the integers "1" or "2" (followed by <Enter >); a plot cannot be generated unless one of these two values is specified. 


\section{Specify Plot Options.}

Three options are available on the control menu to allow the user to modify the output product. An option must be turned on by inputting a " $\mathrm{"} \mathrm{value} \mathrm{or} \mathrm{shut} \mathrm{off} \mathrm{by} \mathrm{inputting} \mathrm{a} \mathrm{"} N$ " value (either value must be followed by <Enter >). Standard selections are "Y" for having wind vectors proportional to speed, " $\mathrm{Y}$ " for outputting numerical data on the plot, and " $\mathrm{N}$ " for labelling station locations on the plot.

\section{Generate a Wind Plot.}

After all options are specified on the control menu, press the <Esc $>$ key (located in the upper left corner of the standard PC keyboard) to initiate the generation of a wind plot. The plot will appear on the screen in several seconds. Wind vectors are centered on the location they represent and indicate the direction toward which the wind is blowing. The plot will remain on the screen until the user selects either the "P" to plot or " $Q$ " to quit option.

\section{Generate a Hard Copy.}

If the user chooses to generate a hard copy of the plot, they must press "P" (<Enter > is not required). An HP laser printer must be properly configured and connected to their system to generate this plot (see Section 3). The plot, depending on its complexity, may take several minutes to be generated-during this time the keyboard will lock up and the user must wait for the operation to be completed.

\section{Exiting the Plot.}

To terminate the PLTWIND session or generate a new plot, the user needs to press "Q". The question "Look at Another?" will appear. Press "Y" to return to the main control menu. Press "N" to terminate the PLTWIND session. 


\subsection{References}

Glantz, C. S., and M. M. Islam. 1988. The Data Collection Component of the Hanford Meteorology Monitoring Program. PNL-6684, Pacific Northwest Laboratory, Richland, Washington.

Glantz, C. S., M. N. Schwartz, K. W. Burk, R. B. Kasper, M. W. Ligotke, and P. J. Perrault. 1990. Climatological Summary of Wind and Temperature Data for the Hanford Meteorology Monitoring Network. PNL-7471, Pacific Northwest Laboratory, Richland, Washington.

Ramsdell, J. V., T. J. Bander, G. F. Athey, and R. I. Scherpelz. 1988. The MESORAD Dose Assessment Model. NUREG/CR-4000, Vol. 2, U.S. Nuclear Regulatory Commission, Washington, D.C.

Ramsdell, J. V., G. F. Athey, and C. S. Glantz. 1983. MESOI Version 2.0: An Interactive Mesoscale Lagrangian Puff Dispersion Model with Deposition and Decay. NUREG/CR-3344, PNL-4753, prepared by Pacific Northwest Laboratory for the U.S. Nuclear Regulatory Commission, Washington, D.C.

Scherpelz, R. I., T. J. Bander, G. F. Athey, and J. V. Ramsdell. 1986. The MESORAD Dose Assessment Model. NUREG/CR-4000, Vol. 1, U.S. Nuclear Regulatory Commission, Washington, D.C.

Stone, W. A., J. M. Thorp, O. P. Gifford, and D. J. Hoitink. 1983. Climatological Summary for the Hanford Area. PNL-4622, Pacific Northwest Laboratory, Richland, Washington.

U.S. Department of Energy (DOE). 1982. Site Characterization Report for the Basalt Waste Isolation Project. DOE/RL 82-3, Vol. II, U.S. Department of Energy, Office of Terminal Waste Disposal and Remedial Action, Washington, D.C. 
Appendix A

Climate and Behavior of Winds at the Hanford Site 


\section{Appendix A}

\section{Climate and Behavior of Winds at the Hanford Site.}

In this appendix, we briefly review the general climate and the characteristic behavior of nearsurface winds at Hanford meteorological monitoring locations. This information is provided as background information for the user of PLTWIND who may not be familiar with the Site's climate or the spatial and temporal variations in atmospheric transport patterns that are characteristic of the Hanford Site. Knowledge of this behavior can be important when attempting to predict atmospheric transport during an actual atmospheric release.

\section{A.1 General Climate of the Hanford Site}

The climate of the Hanford Site is classified as mid-latitude semiarid (DOE 1982) or mid-latitude desert, depending on the climatological classification scheme being used. Summers are warm and dry with abundant sunshine. Large diurnal temperature variations are common during the summer, resulting from intense solar heating and radiational cooling at night. Daytime high temperatures in June, July, and August occasionally exceed $38^{\circ} \mathrm{C}\left(100^{\circ} \mathrm{F}\right)$. Winters, on the other hand, are cool with occasional precipitation. Outbreaks of cold air associated with modified arctic air masses can reach the area and cause temperatures to drop below $-18^{\circ} \mathrm{C}\left(0^{\circ} \mathrm{F}\right)$. Overcast skies and fog occur frequently in the winter.

All air masses that reach the region undergo some modification resulting from their passage over the complex topography of the Pacific Northwest (DOE 1982). The climate of the region is strongly influenced by the Pacific Ocean and the Cascade Range to the west. The relatively low annual average rainfall of $16.1 \mathrm{~cm}$ (6.3 in.) at the Hanford Meteorology Station is, in large part, due to the rain shadow created by the Cascade Range. These mountains limit much of the maritime influence of the Pacific Ocean, resulting in a more continental-type climate than would exist if the mountains were not present. Maritime influences are experienced in the region during the passage of strong synoptic-scale systems. ${ }^{(a)}$. Maritime air also penetrates into the region through gaps in the Cascade Range (such as the Columbia River Gorge).

The Rocky Mountains to the east and the north are also an important influence on the climate of the region. These mountains play a key role in protecting the region from the more severe winter storms and the extremely low temperatures associated with the modified arctic air masses that move southward through Canada.

Locally, the climate of the Hanford Site is influenced by Yakima Ridge and the Rattlesnake Hills to the west, the Horse Heaven Hills to the south, the Saddle Mountains to the north, and the Columbia River. A comprehensive discussion of the climate of the Hanford Site is presented by Stone et al. (1983).

(a) Synoptic-scale systems have horizontal dimensions of several hundred to over a thousand kilometers. 


\section{A.2 Behavior of the Winds on the Hanford Site}

Winds on the Hanford Site are influenced by large-scale and regional factors, but also show the strong influence of terrain channeling and other local terrain influences. The annual and seasonal directional distribution of winds at monitoring locations on the Hanford Site are discussed in detail by Glantz et al. (1990). The annual distribution of wind directions on the Hanford Site are presented in Figure A.1. In this figure, wind roses for each Hanford monitoring station are plotted on a background map of the Hanford Site. In a wind rose, the length of a line extending from a station location is proportional to the relative frequency at which a wind blows from that direction sector toward the station. All wind roses in this figure were drawn using the same scale; the total length of all the lines projecting from any station should equal the total length of all the lines projecting from any other station.

The frequency distribution of wind direction and wind speed at Hanford monitoring stations and the joint frequency distributions of wind direction, wind speed, and atmospheric stability at Hanford Monitoring stations are presented by Glantz et al. (1990). 


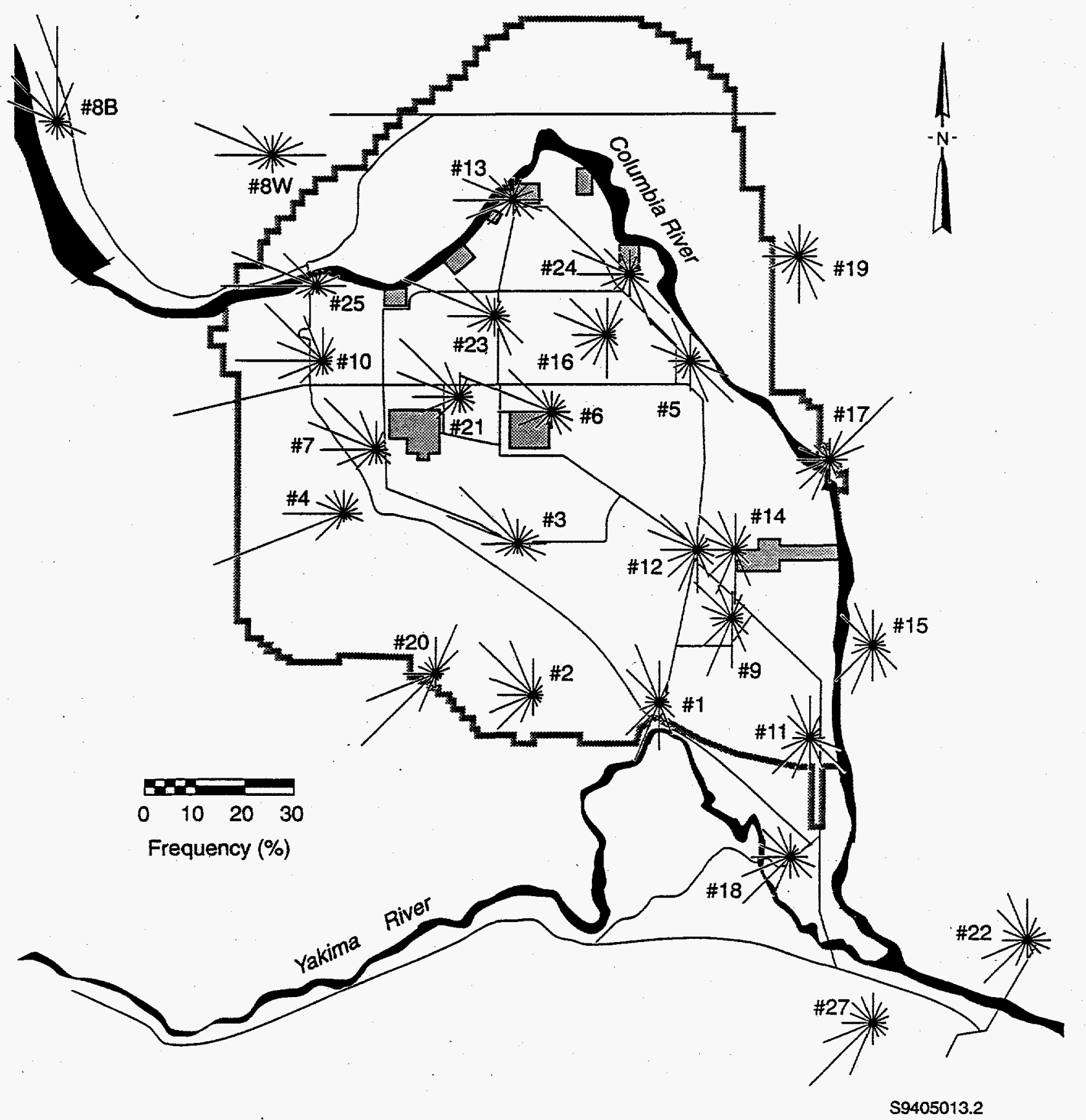

Figure A.1. Annual Wind Roses for the Hanford Site. Based on wind data collected from 1982 through 1993. 
Appendix B

PLTWIND Error Messages 


\section{Appendix B}

\section{PLTWIND Error Messages}

In this appendix, we briefly discuss the error messages that PLTWIND could display on the top line of the control menu. This discussion for each error message reports likely causes of the error and suggests methods for correcting the problem.

\section{"Problem Reading PDATA.DAT at This Time"}

The code has been unable to find and read the PDATA.DAT meteorological data file. An updated file may be in the process of being copied to the user's computer and so may be temporarily unavailable--in such a case the user should wait a few seconds, press a key to acknowledge the message and in response to the question "TRY READING PDATA.DAT AGAIN? (Y OR N)", enter a "Y". Hopefully, the file transfer will be complete and PDATA.DAT will be accessible. Alternatively, the problem may be due to the PDATA.DAT file not residing in the required directory. The file may have been inadvertently deleted and/or the network may not be copying the file to the correct directory. Check the directory for the "PDATA.DAT" file.

\section{"Error in Plot Month"}

The date/time must be associated with a valid record in the PDATA.DAT file; this error message is printed if the input month is not the same as either the month of the first data record or the month of the last data record in PDATA.DAT. Check the input month and make sure that it meets the above criteria.

\section{"Error in Plot Day"}

The date/time must be associated with a valid record in the PDATA.DAT file; this error message is printed if the input day of the month does not meet one of the following criteria:

- the same as the date for the first valid record in PDATA.DAT

- the same as the date for the last valid record in PDATA.DAT

- lies between the dates for the first and last valid records.

Check the input day of the month and make sure that it meets the above criteria.

\section{"Error in Plot Year"}

The date/time must be associated with a valid record in the PDATA.DAT file; this error message is printed if the input year is not the same as either the year of the first data record or the year of the last data record in PDATA.DAT. Check the input year and make sure that it meets the above criteria. 


\section{"Error in Plot Hour"}

The date/time must be associated with a valid record in the PDATA.DAT file; this error message is printed if the input date/hour does not meet one of the following criteria:

- the same date and hour as the first valid record in PDATA.DAT

- the same date and hour as the last valid record in PDATA.DAT

- lies between the dates and hours for the first and last valid records.

Check the input date and hour to make sure that it meets the above criteria.

\section{"Error in Plot Minute"}

The number of minutes must be set to "00", "15", "30", or " 45 "; no other minute input values are acceptable.

Check the input date and time to make sure that it meets the above criteria.

"Error in Plot Minute: Data is Hourly"

The PDATA.DAT file contains only hourly data; minutes must be reset to "00".

\section{"Illegal Wind/Data/Field Selection"}

The only valid output options for the type of plot to be generated are the integers " 1 " (for the plot of monitored winds) and "2" (for the model-generated wind field). All other inputs are illegal. Re-enter the output option for this menu choice by pressing " 1 " or " 2 " followed by <Enter $>$.

\section{"Illegal Response for Vector Type"}

The menu question "Make Wind Vectors Proportional to Speed (Y or N)?" must be responded to with a " $\mathrm{Y}$ " or "N". All other inputs are illegal. Re-enter the output for this menu choice by pressing "Y" or "N" followed by <Enter $>$.

\section{"Illegal Response for NUM. Output"}

The menu question "Full Numerical Output of Monitored Wind Data ( $\mathrm{Y}$ or $\mathrm{N})$ ?" must be responded to with a "Y" or "N". All other inputs are illegal. Re-enter the output for this menu choice by pressing " $\mathrm{Y}$ " or " $\mathrm{N}$ " followed by <Enter $>$.

\section{"Illegal Response for Station Labeling"}

The menu question "Label Station Locations and Names on Plot ( $\mathrm{Y}$ or $\mathrm{N})$ ?" must be responded to with a "Y" or "N". All other inputs are illegal. Re-enter the output for this menu choice by pressing "Y" or "N" followed by <Enter $>$. 


\section{"Error in Data/Time - Integer Values are Required"}

The program was unable to read the user's input for the date or time. Date/time values must be integers values: For the month, use only the values $1-12$. For the day, use only the values 1 31. For the year, use only the last two digits. For the hour, use only the values $0-23$. For the minute, use only the values $0,15,30$, or 45 .

\section{"Error in Data/Time: Check Date/Time Parameters"}

The program detected a problem with the specified date and time. Check all of the input date and time values to make sure that they represent valid date/time combinations for the given PDATA.DAT file. Values must be equivalent to, or located between the first or last valid data record. If the input is correctly formatted, a valid record may not exist in the PDATA.DAT for the date/time combination selected.

\section{"Error in Option Selection: Check all Options"}

An error was detected in one of the menu options after the specification of the date and time. Check the options input for the type of wind plot and make sure that the input for this item is a "1" or "2". All following output options on the menu require the input of either "Y" or "N". Reenter the output options by pressing the appropriate selection followed by $<$ Enter $>$.

\section{"Error in Output File"}

The program was unable to open a required output file. This file is used to save the user's input parameters. The file maybe tied up by another application.

\section{"The MET. Data File is Improperly Formatted"}

While reading the PDATA.DAT file an improperly formatted record was encountered. This problem may be due to one bad data record or the whole file may be bad. To guard against the generation of a plot using erroneous data, the program cannot process the requested data record until the problem with the file is identified and corrected.

\section{"Requested Data Record was not Detected in Current MET Data File"}

The date/time must be associated with a valid record in the PDATA.DAT file; this error message is printed if the input date/hour does not correspond to a valid data record in PDATA.DAT. The requested data record may be missing or have a format problem. Press any key to continue with the message: "SELECT A DIFFERENT DATE/TIME". Press any key to return to the program menu and enter a different date/time for plotting.

\section{"MAP File Nonexistent in Current Directory"}

The file containing the background map for the Hanford Site is not present in the required directory (the directory in which PLTWIND is running)--this file is required to generate a graphical plot. 
Appendix C

Description of PLTWIND Software 


\section{Appendix C}

\section{Description of PLTWIND Software}

PLTWIND is based on several established pieces of Hanford Site emergency response software. PLTWIND uses wind-vector-plotting algorithms currently employed on the meteorology workstation at UDAC. PLTWIND's computation of gridded wind fields is based on algorithms from the MESOI model (Ramsdell et al. 1983), a Lagrangian puff atmospheric dispersion model in use on UDAC's meteorology workstation and at other emergency response centers. PLTWIND's plot of wind fields is also based on algorithms developed for MESOI applications on UDAC's meteorology workstation.

\section{1 Computation of Wind Vectors}

After PLTWIND reads the data record to acquire wind data from each monitoring station for a requested date and time, the wind data are subjected to a simple quality assurance check. Wind directions are considered valid if they are between $0^{\circ}$ and $360^{\circ}$. Negative wind directions and wind directions of greater than $360^{\circ}$ are assumed to represent missing data. After relating the wind data for each station to that station's position on the Hanford background map, wind transport vectors are plotted so they are centered directly over their station locations. If wind vectors are to be drawn with their size proportional to the wind speed, a unit length factor is assigned to each vector and then multiplied by the wind speed at that location to create a vector whose length is proportional to the wind speed. The vectors are oriented so that they point in the direction toward which the wind is blowing (i.e., the direction toward which pollutants would be transferred). The value displayed in the average wind transport vector is averaged over the 15 -min period ending at the date and time specified.

Although the plot of observed winds is very similar in appearance to the plot formerly available through the VAX-based system, it involves an entirely different software product. The software used to plot wind vectors was obtained from the system currently operating on the Meteorology workstation at UDAC. This system involves the use of public-domain PC-graphics software developed at the University of Wisconsin.

\section{C.2 Computation of the Model-Generated Wind Field}

The algorithm used to generate wind fields is based on the "WIND" subroutine in the MESOI atmospheric dispersion code (Ramsdell et al. 1983). In PLTWIND, near-surface winds are defined at each grid point on a 21 by 21 modeling domain that covers an area of $80 \mathrm{~km}$ by $80 \mathrm{~km}$. The resulting distance between adjacent grid points is $4 \mathrm{~km}$. The modeling grid and the spatial relationship between grid points and monitoring stations are defined using slightly modified versions of standard MESOI subroutines.

To generate a wind field, data are required from at least one wind-monitoring station. If a monitoring station is located directly at a particular grid point, the winds at that station are automatically assigned to that grid point. If there is only one monitoring station providing valid wind observations for the entire modeling domain (e.g., owing to a failure of the network's communication 
links), the wind at that station is used to represent the winds at each of the domain's grid points. If data are available from more than one station, the computation of the wind at each grid point is based on a distance-weighted interpolation of data from neighboring monitoring stations with valid wind observations. Beginning with the station closest to a particular grid point, and taking subsequent stations in order of increasing distance away, data from a maximum of five stations can be used to interpolate the winds at that grid point. When three stations provide valid wind observations for interpolation to a grid point, all stations located more than $20 \mathrm{~km}$ away are ignored.

The distance-weighted interpolation uses a $1 / r^{2}$ weighting factor (where " $r$ " is the distance from the grid point to the monitoring station in grid units). Other weighting factors (e.g., $1 / \mathrm{r}$ or $1 / \mathrm{r}^{3}$ ) were considered, but the $1 / \mathrm{r}^{2}$ factor was found to produce the most realistic wind interpolations for the Hanford Site. To illustrate how the distance-weighted interpolation works, consider an example involving four monitoring stations with valid wind observations, located at 4, 8, 16, and $24 \mathrm{~km}$ from a grid point (see Figure C.1). With a 4-km spacing between grid points, these stations are located 1, 2, 4 , and 6 grid units away from the grid point. The distance-weighting factors for the winds at these stations are $1,1 / 4,1 / 16$, and $1 / 36$, respectively. Because the most distant station is located more than $20 \mathrm{~km}$ from the grid point, and there are at least three monitoring stations with valid observations closer to the grid point, data from the fourth station will not be used. The result is that those winds observed at the closest station will have the dominant impact on the interpolated wind at the grid point, with winds at the second station having some influence, winds at the third station influence having only a minor impact, and winds at the fourth station having no impact at all.

The use of this type of interpolation scheme for estimating near-surface winds on a gridded domain provides a good compromise between the often conflicting requirements for accuracy and computational speed (Ramsdell et al. 1983). However, there are drawbacks to this approach. Some common problems with the model-generated wind field involve the following issues:

- The model shows some localized regions with excessive atmospheric convergence and divergence. In the real world, wind fields are governed by the physical requirement that the mass of air flowing into a region must approximately equal the mass of air flowing out of that region. The distanceweighted interpolation method does not prevent the excessive buildup of air in one area or the formation of a partial vacuum.

- When winds are light and variable, winds at individual monitoring stations may not be characteristic of winds at other locations. The model tends to organize winds into coherent patterns that may not actually exist.

- Near-surface winds near a significant terrain feature may differ substantially from the winds at nearby monitoring stations because of the physical obstruction of wind flow or the development of local, thermally driven circulation patterns. Thus, usefulness of the model-generated wind field near significant terrain features (e.g., Rattlesnake Mountain) is limited.

- Significant terrain features may separate areas with quite differing wind flow regimes. For example, the wind observations at the summit of Rattlesnake Mountain tend to dominate the wind field projected for the Yakima Valley (south of Rattlesnake Mountain); however, winds in the valley are known to be generally slower and to have a different direction from that observed at the summit of the mountain. In the absence of a wind-monitoring station within the Yakima Valley, the model does a poor job in projecting winds in the valley. 


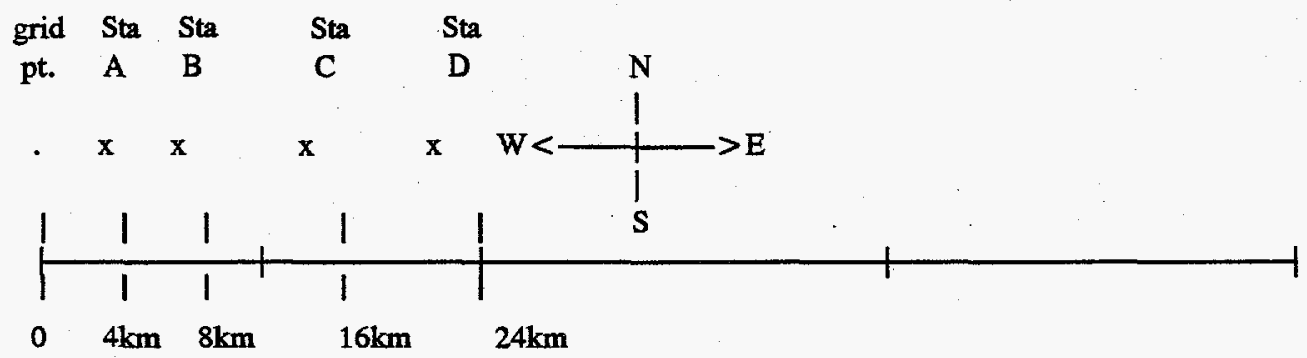

\begin{tabular}{cccccc}
\hline $\begin{array}{c}\text { Sta. Name } \\
\text { (ID) }\end{array}$ & $\begin{array}{c}\text { East-West } \\
\text { Component of } \\
\text { Wind (mph) }\end{array}$ & $\begin{array}{c}\text { North-South } \\
\text { Component of } \\
\text { Wind (mph) }\end{array}$ & $\begin{array}{c}\text { Distance } \\
\text { from grid } \\
\text { point (km) }\end{array}$ & $\begin{array}{c}\text { Distance } \\
\text { from grid } \\
\text { point (units) }\end{array}$ & $\begin{array}{c}\text { Weighting } \\
\text { Factor } \\
\left(1 / r^{2}\right)\end{array}$ \\
\hline A & 4 & 4 & 4 & 1 & 1 \\
B & 6 & 2 & 8 & 2 & 0.25 \\
C & 8 & 0 & 16 & 4 & 0.0625 \\
D & -2 & -2 & 24 & 6 & $0^{(a)}$ \\
\hline
\end{tabular}

(a) The weighting factor is " 0 " because Station D is located more than $20 \mathrm{~km}$ from the grid point and there are at least three closer monitoring stations with valid observations.

East-West

Component of Winds at $=\underline{\Sigma}$ (weighting factor) $\times$ (component of the wind speed) $\Sigma$ weighting factors

grid point

$$
=\frac{4 \mathrm{mph}+(0.25 \times 6 \mathrm{mph})+(0.0625 \times 8 \mathrm{mph})}{1+0.25+0.0625}=\frac{6 \mathrm{mph}}{1.3125}=4.6 \mathrm{mph}
$$

North-South

Component of Winds at

$=\Sigma$ (weighting factor) $\times$ (component of the wind speed) $\Sigma$ weighting factors

grid point

$$
=\frac{4 \mathrm{mph}+(0.25 \times 2 \mathrm{mph})+(0.0625 \times 0 \mathrm{mph})}{1+0.25+0.0625}=\frac{4.5 \mathrm{mph}}{1.3125}=3.4 \mathrm{mph}
$$

In this example, the interpolated wind at the grid point has an east-west component of 4.6 mph and a north-south component of $3.4 \mathrm{mph}$

This is equivalent to an interpolated wind at the grid point from $217^{\circ} \mathrm{N}$ (the south-southwest) with a net speed of $5.7 \mathrm{mph}$.

Figure C.1. Example of a $1 / r^{2}$ Distance-Weighted Interpolation 
- When winds blow in opposite directions at adjacent wind monitoring stations, the resulting interpolation may show a region in which wind speeds drop to zero because of the vector addition of opposing grid components.

In view of these drawbacks, it is important that model-generated wind fields be used only as a general guide in estimating area winds. In addition to the model products, Hanford Meteorology Station and UDAC meteorologists use other data sources and their professional judgement in assessing near-surface wind fields in the Hanford area. Users of PLTWIND should consult the UDAC meteorology team for guidance if they encounter conflicting assessments of near-surface wind fields or are uncertain about model results. 
Appendix D

Sample PLTWIND Test Cases 


\section{Appendix D}

\section{Sample PLTWIND Test Cases}

In this section, we present the meteorological data input file, control menus, and output products for a series of four PLTWIND model runs. The purpose of this section is to provide the user with some benchmark test cases that can be used for training and quality assurance purposes.

The monitoring station location file (CENTSTA.DAT) used in these tests contains the data presented in Table 2.1. All of the test cases use the sample meteorological data file (PDATA.DAT) presented in Figure D.1. This test file has the same format as any other PDATA.DAT file, but it contains fewer data records.

\section{D.1 PLTWIND Test Case 1}

This case is designed to test PLTWIND using extremely simple meteorological input. Figure D.2 represents the control menu created by the user to plot the observed wind data for the first data record in the sample meteorological data input file, with wind vector length made proportional to wind speed, full numerical output, and no station labeling. Note that the control menu displays the date as the day of the month (August 26, 1992) and the time in PDT (01:15), successfully converting from the Julian day (day 239) and standard time value (00:15) presented in the data file.

The wind plot generated using this control menu is presented in Figure D.3. In this simplified first example, all of the monitoring stations are reporting the same direction and speed. The wind plot correctly displays this basic situation. The wind field plot for this record is presented in Figure D.4. The wind vectors at all of the grid points are identical (as expected given the identical wind data reported at each monitoring stations).

\section{D.2 PLTWIND Test Case 2}

This case is designed to test PLTWIND using meteorological data input that has a constant wind direction but varying wind speeds. Figure D.5 represents the control menu created by the user to plot the observed wind data for the second data record in the sample meteorological data input file. In the requested data record, all wind observations have the same direction but each wind speed is increased by $1 \mathrm{mph}$ over the value reported for the previous station. The wind plot generated using this control menu is presented in Figure D.6. Note that the wind vector for Pasco is truncated as the vector passes beyond the right margin of the plotting area. The sizes of all other displayed wind vectors are proportional to their wind speeds. In Figure D.7, the same data are plotted, but for this plot the wind vectors are not drawn proportional to the wind speed. 
[blank line]

MET 1:/datafs > cat pdata.dat

$9423901517 \quad 0 \quad 2705270527052705270527052705270527052705$

$9423901527 \quad 0 \quad 2705270527052705270527052705270527052705$

$\begin{array}{lllllllllllllll}94239 & 01537 & 0 & 2705 & 2705 & 2705 & 2705 & 2705 & 2705 & 8888 & 8888 & 8888 & 8888\end{array}$

$\begin{array}{lllllllllllll}94239 & 03017 & 0 & 2701 & 2702 & 2703 & 2704 & 2705 & 2706 & 2707 & 2708 & 2709 & 2710\end{array}$

$\begin{array}{lllllllllllll}9423903027 & 0 & 2711 & 2712 & 2713 & 2714 & 2715 & 2716 & 2717 & 2718 & 2719 & 2720\end{array}$

$\begin{array}{lllllllllllll}94239 & 0303 & 0 & 2721 & 2722 & 2723 & 2724 & 2725 & 2726 & 8888 & 8888 & 8888 & 8888\end{array}$

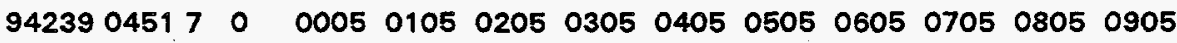

$\begin{array}{llllllllllllllll}94239 & 04527 & 0 & 1005 & 1105 & 1205 & 1305 & 1405 & 1505 & 1605 & 1705 & 1805 & 1905\end{array}$

$\begin{array}{lllllllllllll}94239 & 04537 & 0 & 2005 & 2105 & 2205 & 2305 & 2405 & 2505 & 8888 & 8888 & 8888 & 8888\end{array}$

9423910017002605270528052905300531053205330534053505

$9423910027 \quad 0 \quad 3605370538053905400541054205430544054505$

$\begin{array}{llllllllllllllll}94239 & 1003 & 7 & 0 & 4605 & 4705 & 4805 & 4905 & 5005 & 5105 & 8888 & 8888 & 8888 & 8888\end{array}$

$\begin{array}{lllllllllllll}94239 & 11517 & 0 & 8888 & 8888 & 8888 & 8888 & 8888 & 8888 & 8888 & 2705 & 8888 & 8888\end{array}$

$\begin{array}{llllllllllllllll}94239 & 1152 & 7 & 0 & 8888 & 8888 & 8888 & 8888 & 8888 & 8888 & 8888 & 8888 & 8888 & 8888\end{array}$

$\begin{array}{llllllllllllll}94239 & 1153 & 7 & 0 & 2705 & 2705 & 8888 & 8888 & 8888 & 8888 & 8888 & 8888 & 8888 & 8888\end{array}$

$\begin{array}{lllllllllllllll}94239 & 1301 & 7 & 0 & 8888 & 8888 & 8888 & 8888 & 8888 & 8888 & 8888 & 0005 & 8888 & 8888\end{array}$

$\begin{array}{llllllllllllllll}94239 & 13027 & 0 & 8888 & 8888 & 8888 & 8888 & 8888 & 8888 & 8888 & 8888 & 8888 & 8888\end{array}$

$\begin{array}{llllllllllllllll}94239 & 13037 & 0 & 0005 & 0005 & 8888 & 8888 & 8888 & 8888 & 8888 & 8888 & 8888 & 8888\end{array}$

$\begin{array}{llllllllllllll}94239 & 1451.7 & 0 & 8888 & 8888 & 8888 & 8888 & 8888 & 8888 & 8888 & 0005 & 8888 & 8888\end{array}$

$\begin{array}{lllllllllllllll}94239 & 14527 & 0 & 8888 & 8888 & 8888 & 8888 & 8888 & 8888 & 8888 & 8888 & 8888 & 8888\end{array}$

$\begin{array}{lllllllllllllllll}94239 & 1453 & 7 & 0 & 8888 & 1805 & 8888 & 8888 & 8888 & 8888 & 8888 & 8888 & 8888 & 8888\end{array}$

Figure D.1. The Input Meteorological Data File Used for Model Testing 
CONTROL MENU FOR PLOTTING HANFORD WIND OBSERVATIONS AND WIND FIEIDS

Use the up and down arrows to move from line to line.

Enter requested data and hit <ENTER> to lock-in the input value.

The Wind Data File tas 15-Minute Resolution.

File Begins - $8 / 27 / 94$ at $1: 15$ PDT

File Ends - 8/27/94 at 2:45 PDT

Plot Data For -- MONTH : 8

DAY : 27

YEAR : 94

HR (PDT): 1

MINUTES : 15

Output options: 1: Plot of Monitored Wind Directions

2: Model-Generated Wind Fields

Enter Selected option ("I" or "2"): 1

Make wind Vectors Proportional to speed ( $Y$ or $N$ ) ?: $Y$.

Full Numerical output of Monitored Wind Data ( $Y$ or $N$ ) ?: $Y$

Label station Locations and Names on Plot ( $Y$ or $N)$ ?: $N$

Hit <Esc> to plot, <End> to abort, <Insert> to update the wind data file.

Figure D.2. Control Menu for Test Case 1 

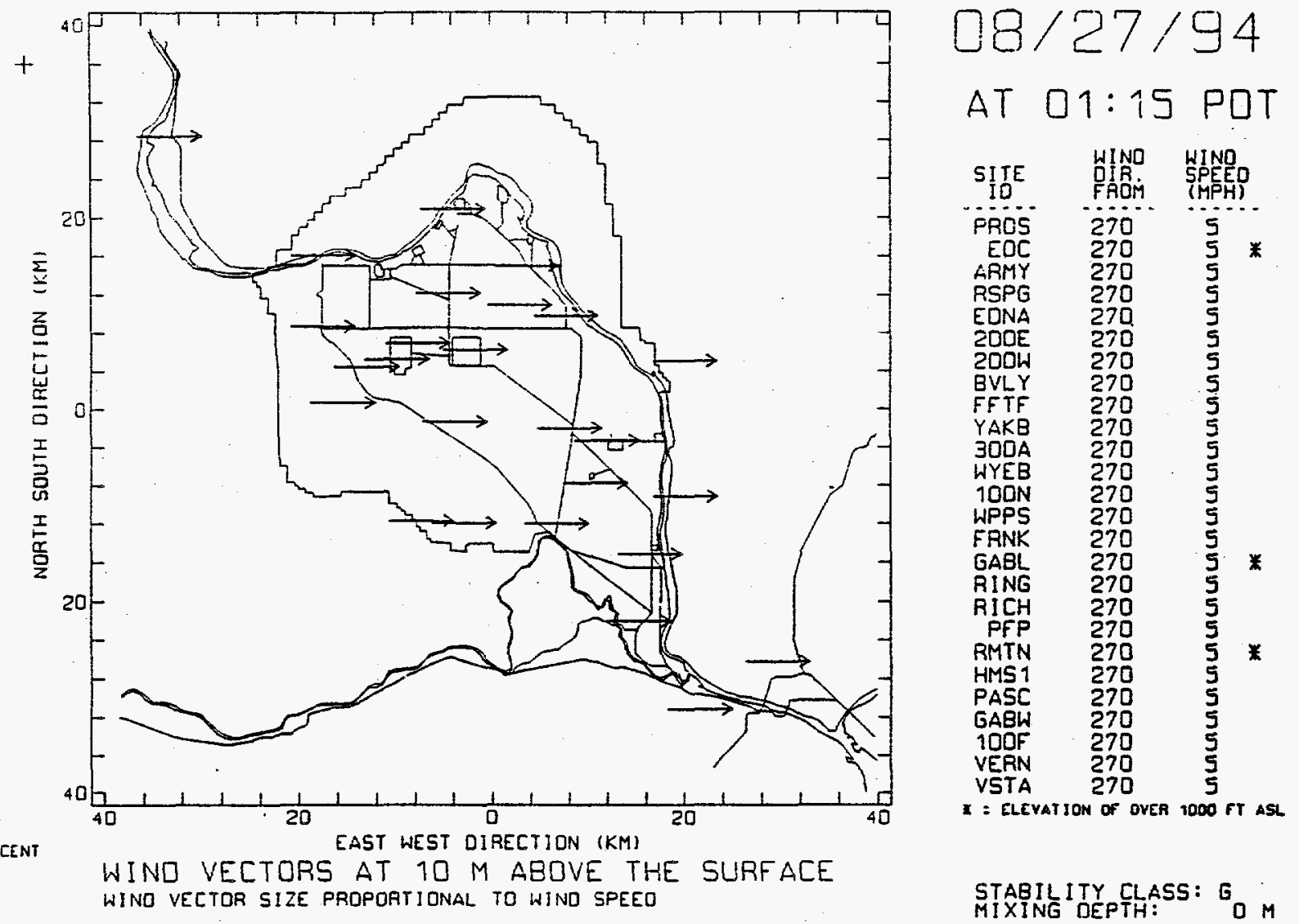

Figure D.3. Plot of Monitored Winds for Test Case 1. All stations are reporting a wind direction of $270^{\circ}$ with a speed of $5 \mathrm{mph}$. 


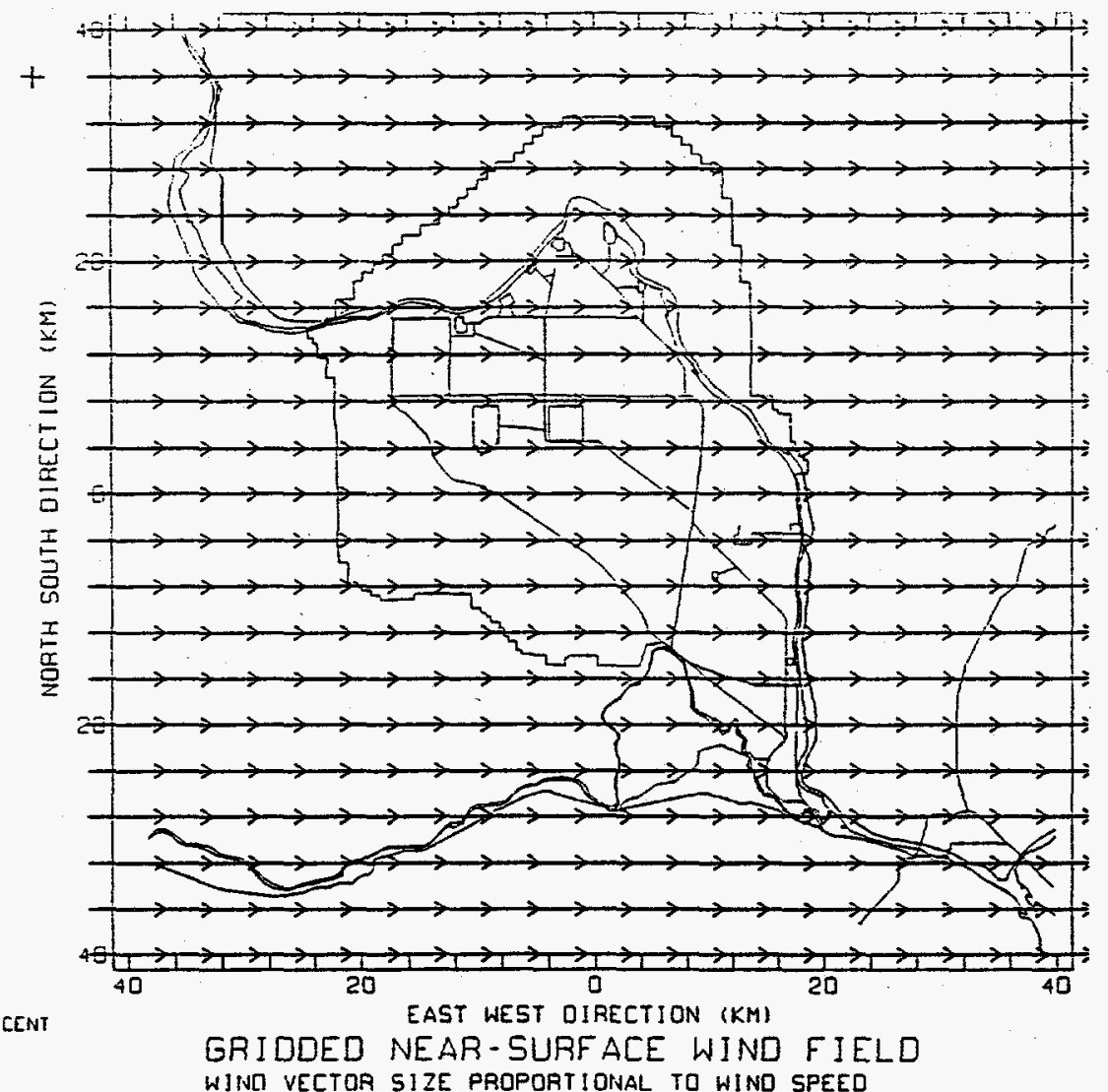

$08 / 27 / 94$

AT 01:15 POT

SITE WINO WINO

STge

PROS

EOC

ARMY

RSPG

EDNA

2005

$200 \mathrm{~W}$

EVLY

FFTF

YAKB

$300 A$

WYEB

$100 \mathrm{~N}$

WPPS

FRNK

GABL

RING

RICH

PFP

RMTN

HMS 1

PASC

GABW

$100 \mathrm{~F}$

VERN

FAOA (MPH)

270

270

270

270

270

270

270

270

270

270

270

270

270

270

270

270

270

270

270

270

270

270

$\frac{5}{5} *$

VSTA

x = Elevation of over $1000 \mathrm{ft}$ asL

MAX. WINO SPQ: OS MPH

WIINO VECTOR SIZE PROPORTIONAL TO WINO SPEED

Figure D.4. Wind Field Plot for Test Case 1. All of the winds on the modeling grid are identical, reflecting the identical winds at the monitoring stations. 
CONTROL MENU FOR PLOTTING HANFORD WIND OBSERVATIONS AND WIND FIELDS

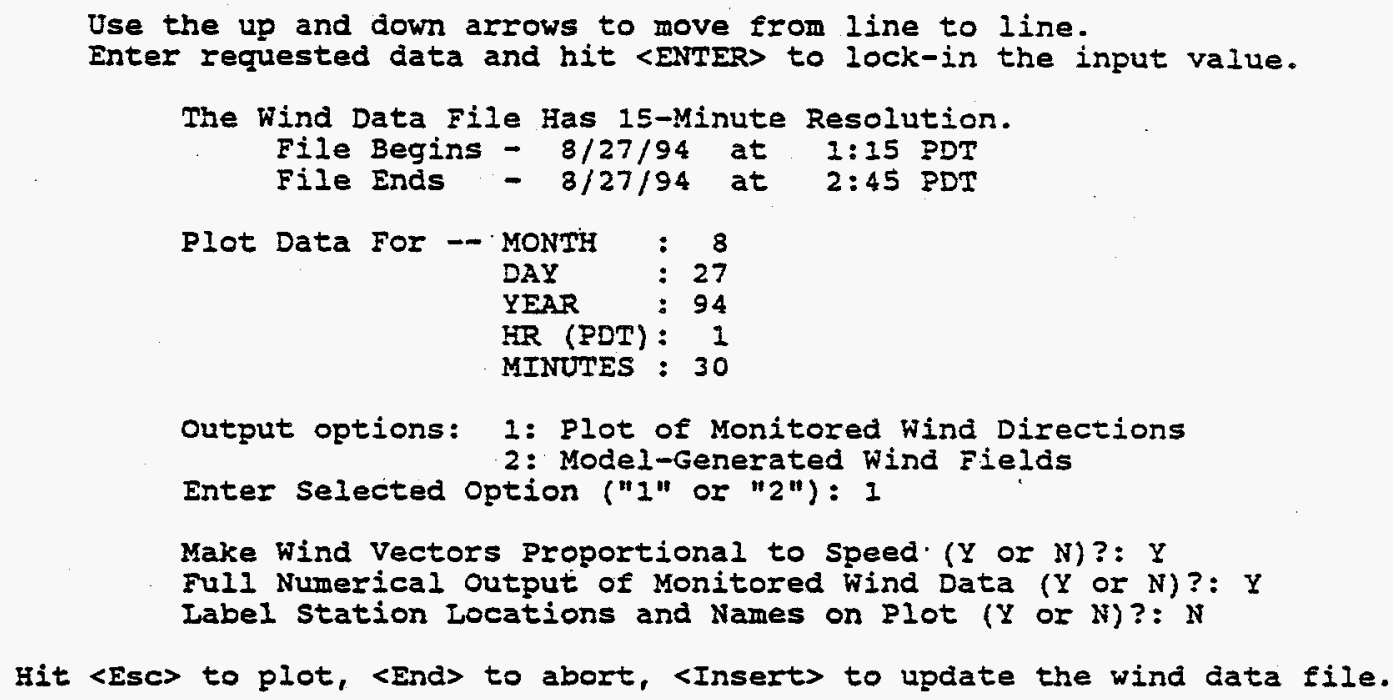

Figure D.5. Control Menu for Test Case 2 

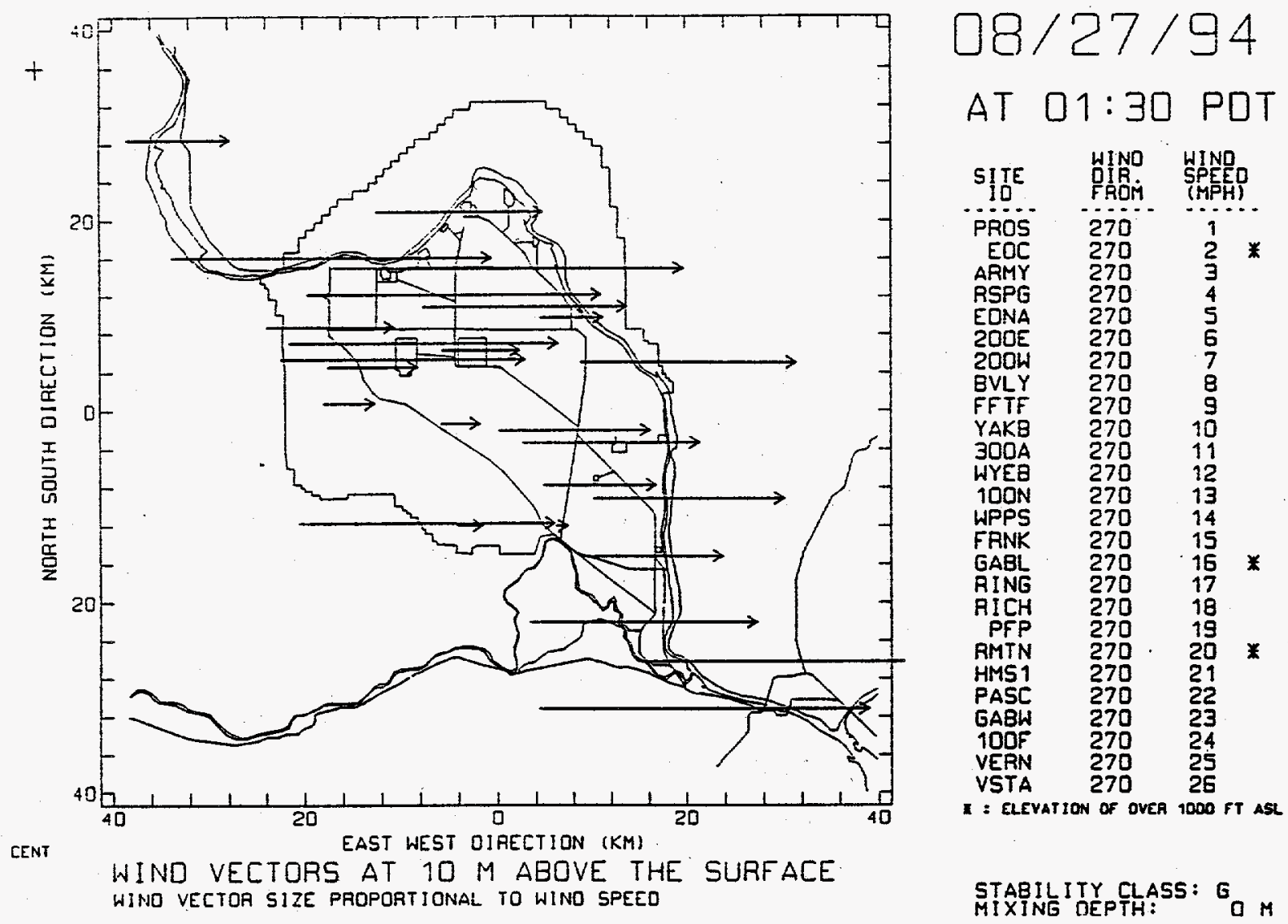

Figure D.6. Plot of Monitored Winds for Test Case 2 with Winds Proportional to Wind Speed. All stations are reporting a wind direction of $270^{\circ}$. but different wind speeds. 


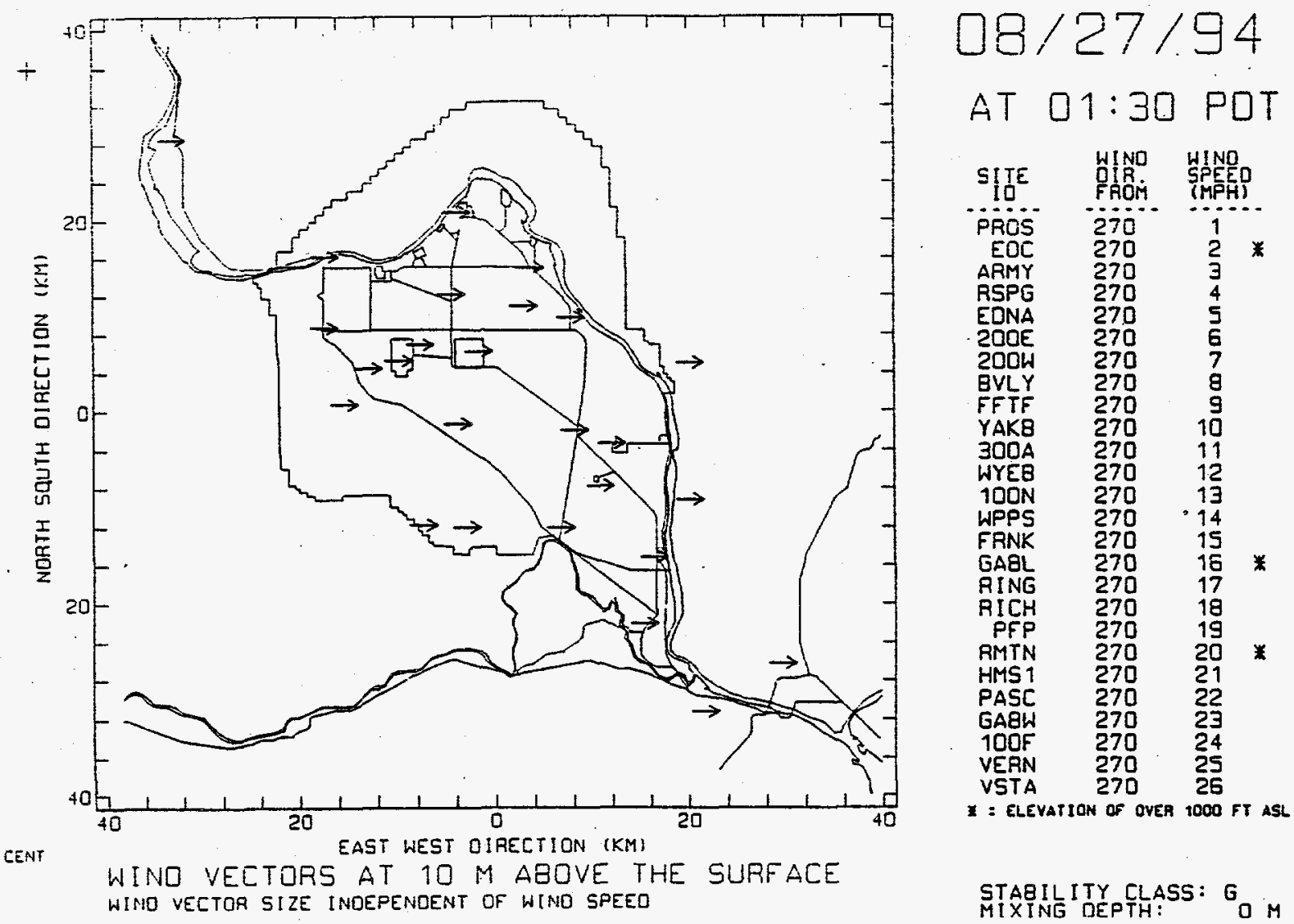

Figure D.7. Plot of Monitored Winds for Test Case 2 with Vector Length Independent of Wind Speed. All stations are reporting a wind direction of $270^{\circ}$ but different wind speeds. 


\section{D.3 PLTWIND Test Case 3}

This case is designed to test PLTWIND using meteorological data input that has varying wind directions but a constant wind speed. Figure D. 8 represents the control menu created by the user to plot the observed wind data for the third data record in the sample meteorological data input file. In the requested data record, all wind observations have the same wind speed but the wind direction at each station increases by $10^{\circ}$ from that reported from the previous station (the first wind station [PROS] reports a wind of $0^{\circ}$ and the last of the 26 active stations reports a wind of $250^{\circ}$ ). The wind plot generated using this control menu is presented in Figure D.9.

Figure D.10 presents the wind data plotted for the fourth data record. This data record begins where the third data record left off - the first wind station (PROS) reports a wind direction of $260^{\circ}$ and the wind direction increases by $10^{\circ}$ for each subsequent station. Note that after a wind direction of $360^{\circ}$ is registered for the Yakima Barricade, subsequent wind data (with still greater wind direction angles) are not plotted - the PLTWIND code assumes that any reported wind direction greater than $360^{\circ}$ either is incorrect or represents missing data.

\section{D.4 PLTWIND Test Case 4}

This case is designed to test the spatial variation in the model-generated wind field using limited meteorological data input. Figure D.11 presents the control menu created by the user to plot the observed wind data for the last data record in the sample meteorological input file. In the requested data record, only two wind stations are active (BVLY and PASC) and these stations have opposing wind directions and identical speed. The wind plot generated using this control menu is presented in Figure D.12. The wind field plot for this record is presented in Figure D.13. Note how the data from each station dominate its immediate surroundings, but at grid points at comparable distances from each station the opposing winds tend to cancel out. Along a diagonal line representing grid points equidistance from the monitoring stations, the wind field goes to zero.

Having opposing winds at distant stations is not an unusual phenomenon, but the wind field generated by the model for the region between these stations is not representative of how winds would actually flow in the real world. This example illustrates both how the $1 / \mathrm{r}^{2}$ distance interpolation works in a simplified setting, and how simplified assumptions used by the model can cause wind field projections that are not representative of real-world conditions. The user must keep in mind that model-generated wind fields should be used only as a general guide for estimating near-surface winds in the Hanford area. 
CONTROL MENU FOR FLOTTING HANEORD WIND OBSERVATIONS AND WIND FIELDS

Use the up and down arrows to move from line to line.

Enter requested data and hit <ENTER> to lock-in the input value.

The Wind Data File Has 15-Minute Resolution.

File Begins - $8 / 27 / 94$ at $1: 15$ PDT

File Ends $-8 / 27 / 94$ at $2: 45$ PDT

Plot Data For -- MONTH : 8

DAY : 27

YEAR : 94

ER (PDT): 1

MINUTES : 45

Output options: 1: Plot of Monitored Wind Directions

2: Model-Generated wind Fields

Enter Selected Option ("1" or "2"): 1

Make Wind Vectors Proportional to speed ( $Y$ or $N$ )?: $Y$

Full Numerical output of Monitored Wind Data ( $Y$ or $N$ ) ?: $Y$

Label station Locations and Names on Plot ( $Y$ or $N$ ) ?: $N$

git <Esc> to plot, <End> to abort, <Insert> to update the wind data file.

Figure D.8. Control Menu for Test Case 3 


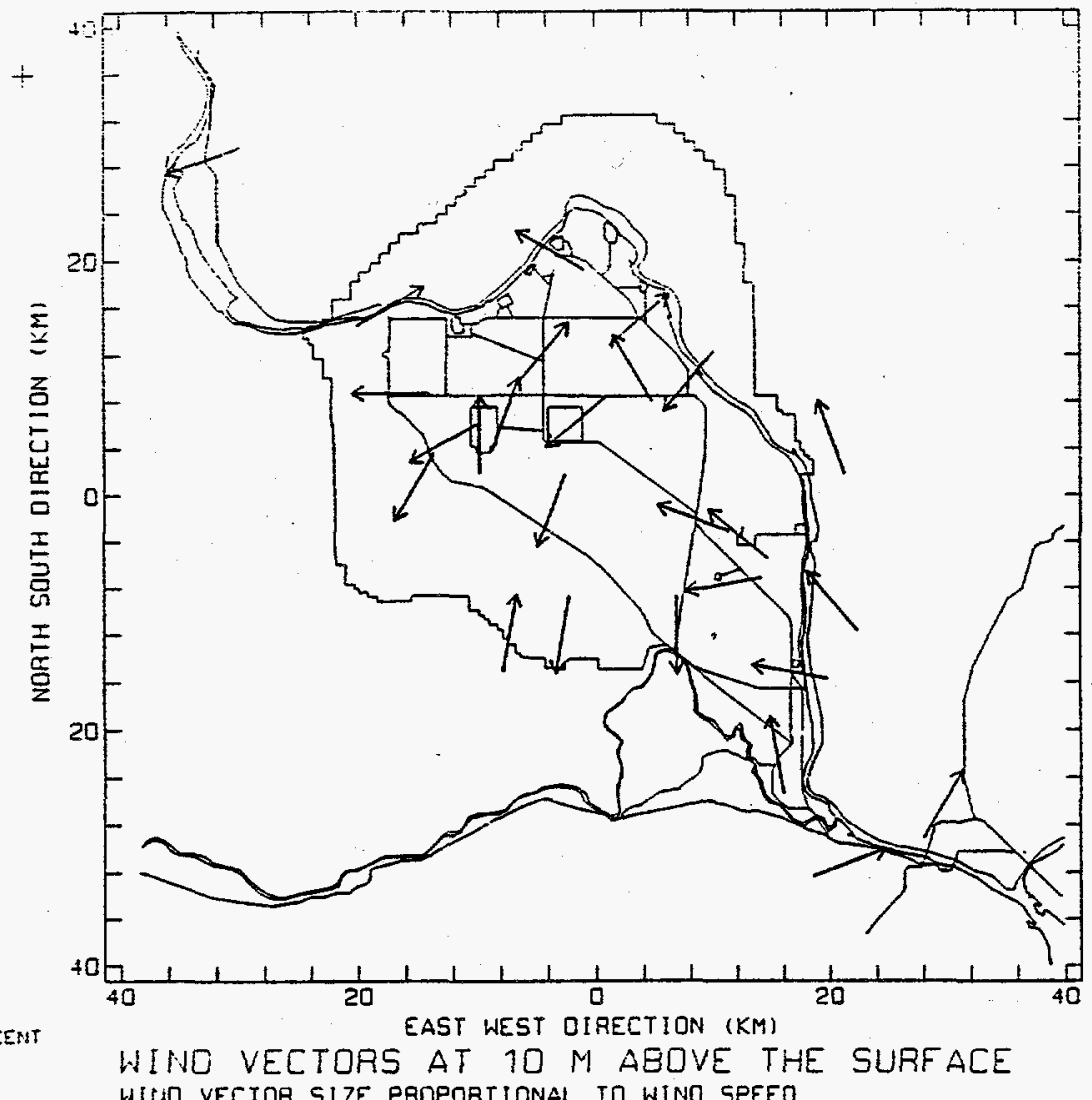

$08 / 27 / 94$

AT 01:45 POT

SITE WLINO HINO

TIOE FROA SMPH?

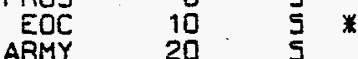

ARMY

RSPG

EDNA

$200 E$

200W

BVLY

FFTF

YAKB

WOOA

$100 \mathrm{~N}$

WPPS

FRNK

GABL

AING

RICH

RMTN

HMS 1

PASC

GABW

100F

VERN

VSTA

20

30
40

50

60

70

80

100

110

120

130

140

150

160

170

180

190

200

210

220

230

240

I : Elevation of OVER tCOO ET ASL WITI VECTOR SIZE PROPORTIONAL TO WINO SPEEO

STABILITY CLASS: G

Figure D.9. Plot of Monitored Winds for Test Case 3 at 01:45 PDT. All stations are reporting a wind speed of $5 \mathrm{mph}$. Wind directions range from $0^{\circ}$ to $250^{\circ}$. 

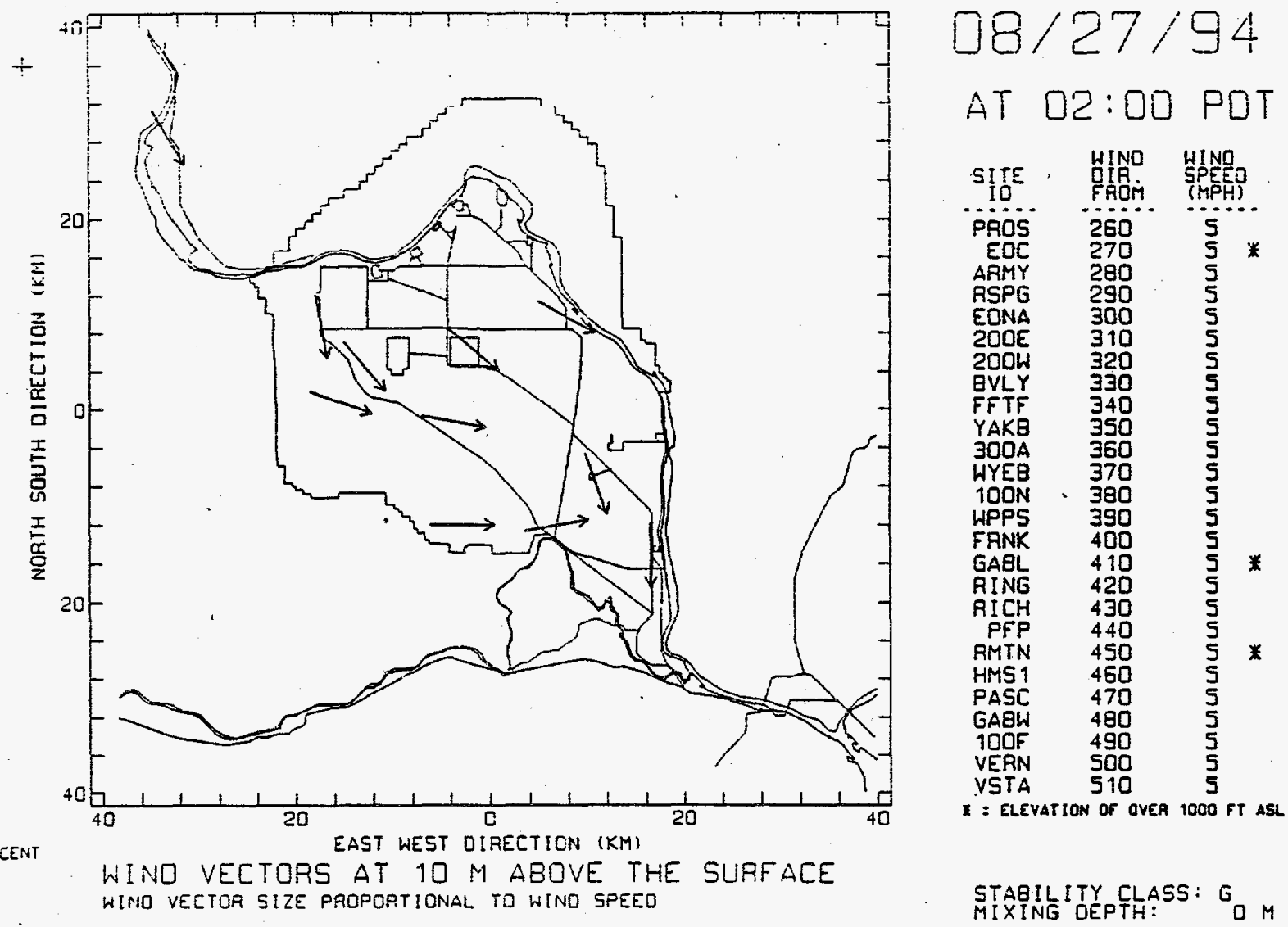

Figure D.10. Plot of Monitored Winds for Test Case 3 at 02:00 PDT. All stations are reporting a wind speed of $5 \mathrm{mph}$. Wind directions range from $260^{\circ}$ to $510^{\circ}$; wind vectors are not plotted when directions are greater than $360^{\circ}$. 
CONTROL MENG FOR PIOTTING HANEORD WIMD OBSERVATIONS AHD WIND FIEIDS

Use the up and down arrows to move from line to line.

Enter requested data and hit <ENTER> to lock-in the input value.

The Wind Data File Has 15-Minute Resolution.

File Begins - 8/27/94 at 1:15 PDT

File Ends - $8 / 27 / 94$ at $2: 45$ PDT

Plot Data For -- MONTH : 8

DAY : 27

YEAR : 94

IIR (PDT): 2

MINUTES : 45

Output options: 1: Plot of Monitored Wind Directions

2: Model-Generated wind Fields

Enter Selected Option ("1" or "2"): 1

Make wind Vectors Proportional to Speed ( $Y$ or $N$ )?: $Y$

Full Numerical Output of Monitored Wind Data ( $Y$ or $N$ )?: $Y$

Label Station Locations and Names on Plot ( $Y$ or $N$ )?: $N$

Hit <Esc> to plot, <End> to abort, <Insert> to update the wind data file.

Figure D.11. Control Menu for Test Case 4 

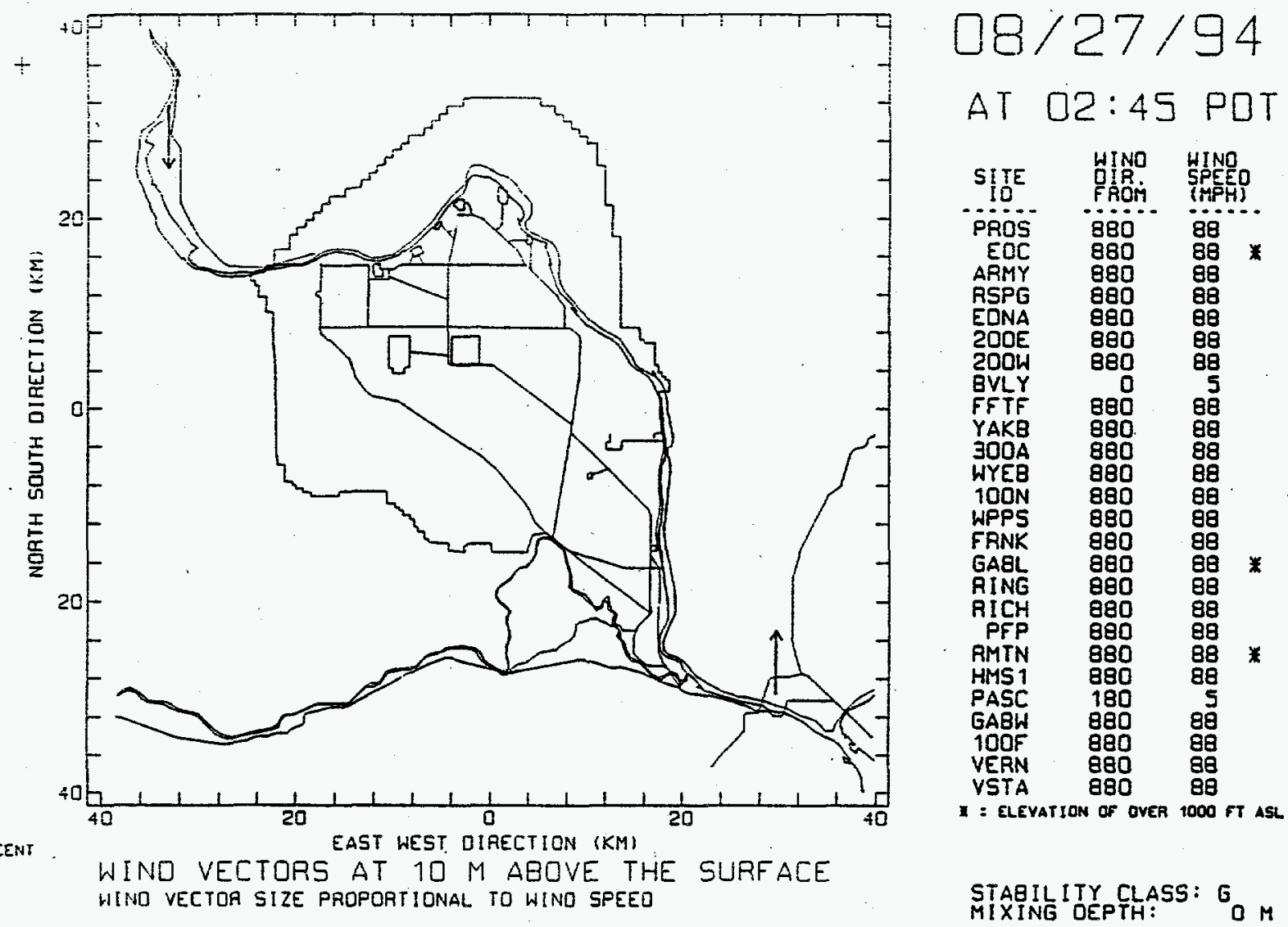

Figure D.12. Plot of Monitored Winds for Test Case 4. Data are provided for only two stations, which have opposing wind directions and a speed of $5 \mathrm{mph}$. 


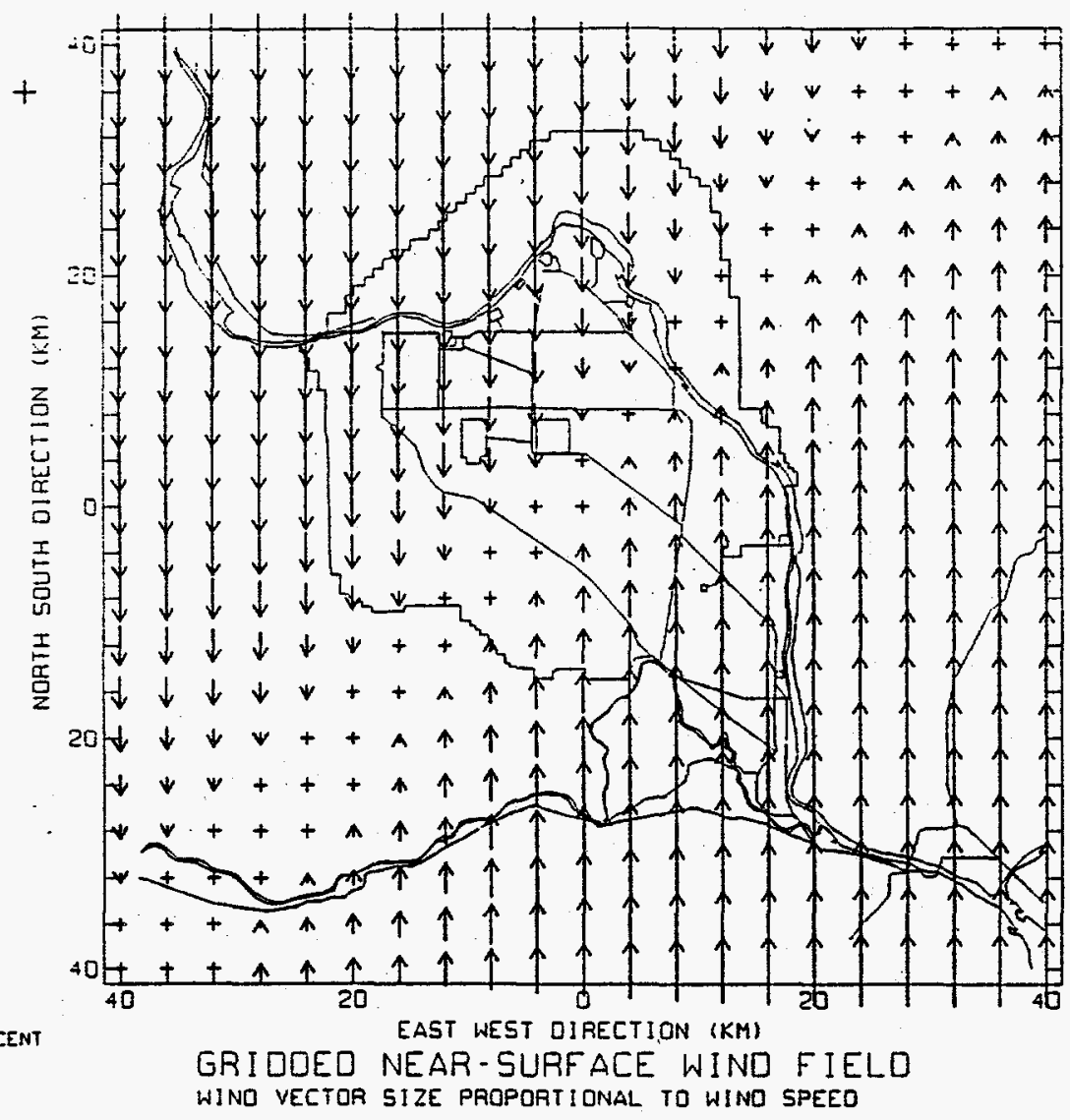

Figure D.13. Wind Field Plot for Test Case 4
$08 / 27 / 94$

AT 02:45 POT

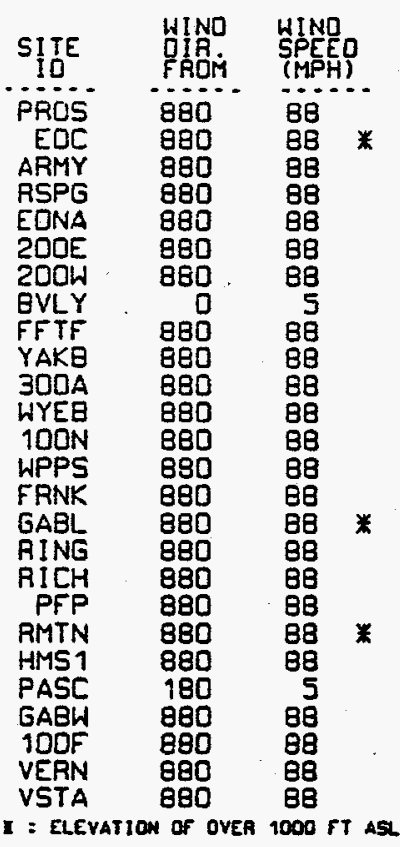

MAX. WINO SPD: DS MPH 


\section{Distribution}

No. of

Copies

ONSITE

13 Westinghouse Hanford Company

L. R. Campbell

D. A. Marsh (10)

E. C. Norman

W. C. Shanklin

17 Pacific Northwest Laboratory

K. W. Burk

J. G. Droppo
A3-05

A3-05

H6-33

A0-20

S3-91

K6-80
No. of

Copies

C. J. Fosmire

K9-30

C. S. Glantz (5)

K6-80

R. I. Scherpelz

P7-03

Information Release

Office (7)

\section{Routing}

R. W. Bryce

K9-34

R. M. Ecker

S. A. Rawson

R. L. Skaggs

K6-91

K9-34

K6-91

P. C. Hays (last)

K9-41 